\title{
Rhizosphere Engineering With Plant Growth-Promoting Microorganisms for Agriculture and Ecological Sustainability
}

\author{
Sughra Hakim ${ }^{1,2+}$, Tahir Naqqash ${ }^{3 \dagger}$, Muhammad Shoib Nawaz ${ }^{1,2}$, Iqra Laraib ${ }^{1,2}$, \\ Muhammad Jawad Siddique ${ }^{1,2}$, Rabisa Zia ${ }^{1,2}$, Muhammad Sajjad Mirza ${ }^{1}$ and \\ Asma Imran ${ }^{1 *}$ \\ ${ }^{1}$ Soil and Environmental Biotechnology Division, National Institute for Biotechnology and Genetic Engineering, Faisalabad, \\ Pakistan, ${ }^{2}$ Department of Biotechnology, Pakistan Institute of Engineering and Applied Sciences, Islamabad, Pakistan, \\ ${ }^{3}$ Biotechnology Division, Institute of Molecular Biology and Biotechnology, Bahauddin Zakariya University, Multan, Pakistan
}

The rhizosphere is undoubtedly the most complex microhabitat, comprised of an integrated network of plant roots, soil, and a diverse consortium of bacteria, fungi, eukaryotes, and archaea. The rhizosphere conditions have a direct impact on crop growth and yield. Nutrient-rich rhizosphere environments stimulate plant growth and yield and vice versa. Extensive cultivation exhaust most of the soils which need to be nurtured before or during the next crop. Chemical fertilizers are the major source of crop nutrients but their uncontrolled and widespread usage has posed a serious threat to the sustainability of agriculture and stability of an ecosystem. These chemicals are accumulated in the soil, drained in water, and emitted to the air where they persist for decades causing a serious threat to the overall ecosystem. Plant growth-promoting rhizobacteria (PGPR) present in the rhizosphere convert many plant-unavailable essential nutrients e.g., nitrogen, phosphorous, zinc, etc. into available forms. PGPR produces certain plant growth hormones (such as auxin, cytokinin, and gibberellin), cell lytic enzymes (chitinase, protease, hydrolases, etc.), secondary metabolites, and antibiotics, and stress alleviating compounds (e.g., 1-Aminocyclopropane-1- carboxylate deaminase), chelating agents (siderophores), and some signaling compounds (e.g., N-Acyl homoserine lactones) to interact with the beneficial or pathogenic counterparts in the rhizosphere. These multifarious activities of PGPR improve the soil structure, health, fertility, and functioning which directly or indirectly support plant growth under normal and stressed environments. Rhizosphere engineering with these PGPR has a wide-ranging application not only for crop fertilization but developing eco-friendly sustainable agriculture. Due to severe climate change effects on plants and rhizosphere biology, there is growing interest in stress-resilient PGPM and their subsequent application to induce stress (drought, salinity, and heat) tolerance mechanism in plants. This review describes the three components of rhizosphere engineering with an explicit focus on the broader perspective of PGPM that could facilitate rhizosphere engineering in selected hosts to serve as an efficient component for sustainable agriculture.

Keywords: plant growth promoting bacteria, rhizosphere engineering, stress tolerance, microbiome, plant growth promotion 


\section{INTRODUCTION}

The development of healthy human societies depends upon the availability of food which is one of the basic needs for human beings. The rapid increase in the human population, climate changes encompassing biotic and abiotic stresses, and land scarcity have imposed an undesirable impact on global food production. Food insecurity is a chronic issue that is likely to worsen as the human population is expected to be more than 9 billion by 2050 (Kumar and Dubey, 2020). The population increase-mediated pressure in agriculture has led to intensive use of chemical fertilizers, and pesticides to get the maximum yield out of the existing agricultural lands. Of the total, around $20-30 \%$ of the applied fertilizer is taken up by the plant. Most of the crop varieties have low nutrient uptake efficiencies. Due to low nutrients use efficiency in agriculture and soil dynamics, more than $50 \%$ of applied chemical fertilizers are lost to the environment (Fageria, 2014). Furthermore, many of the plant varieties developed in the background of the "green revolution" have become non-responsive to the fertilizers and their yields are stagnant. Both nitrogen and phosphorus fertilizers added to the soil are readily volatilized, rapidly washed-off, gradually converted to un-available forms due to natural processes making the ecosphere and biosphere at higher risk for future generations. As a consequence of this, the overall agriculture production decreased along with several environmental problems such as loss of biodiversity, emission of greenhouse gases, water pollution, and soil contamination. It has subsequently deteriorated soil biology and its health. Furthermore, the higher cost of agriculture input and low-cost benefits are also affecting the farmer's interest. Due to these reasons, the agriculture system is under tremendous pressure and its sustainability is essential for (i) the management of food security for increasing demand (ii) mitigation of adverse climatic effects and changes (iii) improvement in soil quality and nutrient (Lal, 2015).

Over the past decades, sustainable food and agriculture production (SFAP) has become one of the world's most fundamental needs for food security. SFAP is an approach for the production of food and fiber in balance with a protected environment and public health. It includes the usage of resources more efficiently with minimized adverse effects on the environment, restore and preserve the quality of soil and water along with improved productivity. Per this definition, food provision to humans, enhanced natural resources with high resource use efficiency, and improved quality of life has been considered as the general goals of sustainable agriculture production (Walters et al., 2016).

Several strategies have been employed for enhancing the nutrient use efficiency (NUE) of crops and sustainable agriculture production. Of these approaches, the $4 \mathrm{R}$ strategy is more recently introduced that includes the use of the Right Source of nutrients at the Right Rate, Right Time, and in the Right Place. This strategy can be further expanded and made more comprehensive if we

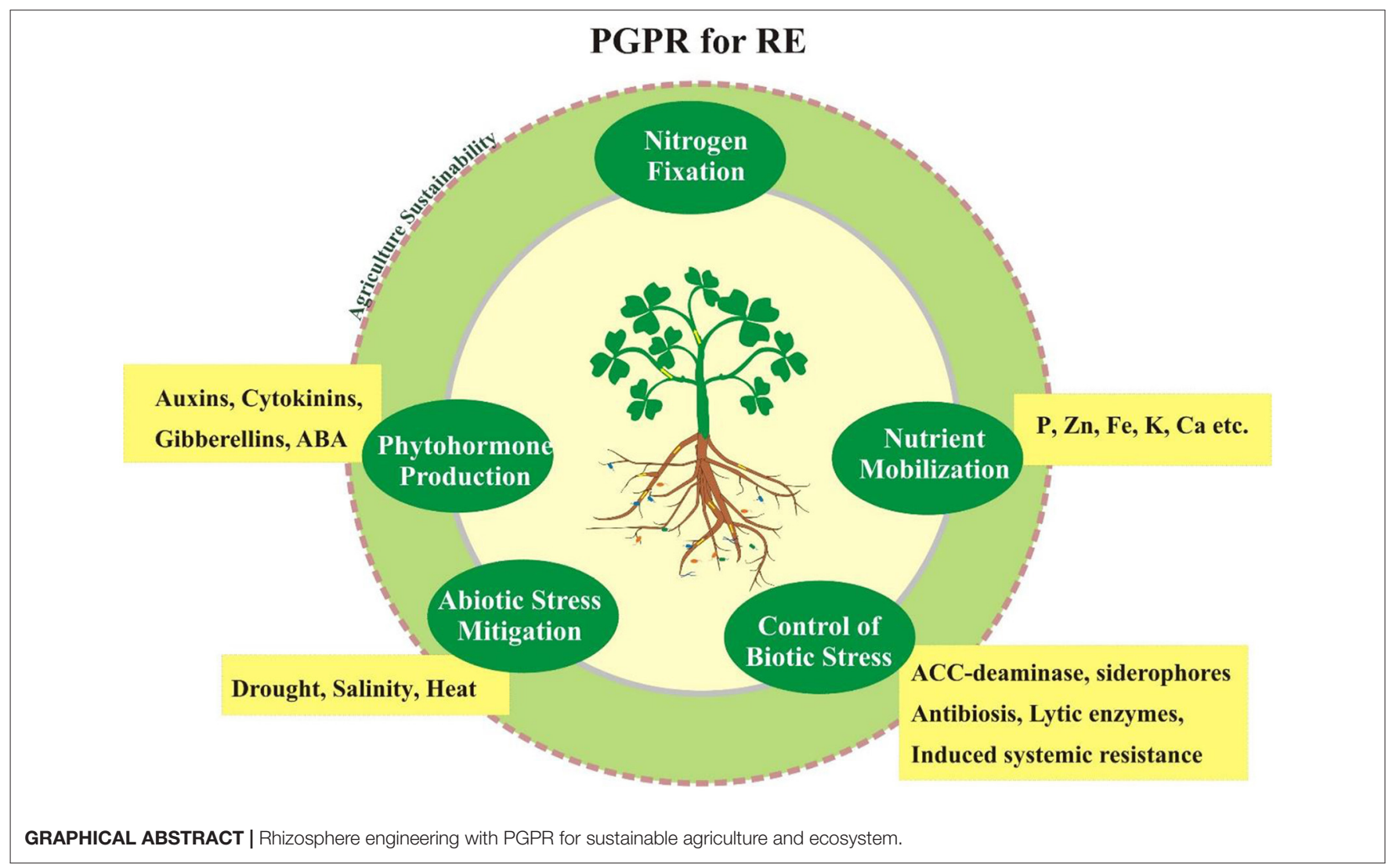


include two major players in this interaction i.e., the plant which is using the nutrient and the rhizosphere where the nutrients are applied. In this scenario, the emphasis should be focused on the selection of low-fertilizer responsive crop germplasm and incorporation (inoculation) of the Right plant growth-promoting bacteria for rhizosphere engineering. Plant breeding or plant engineering is a separate branch that has been the subject of many comprehensive reviews published. The current review will focus on the rhizosphere engineering (RE) using PGPR with special reference to plant benefits, nutrient uptake, and ecological sustainability.

\section{RHIZOSPHERE ENGINEERING (RE)}

\section{What Is RE}

The rhizosphere is the narrow zone of soil that is in direct proximity to plant roots and the hotspot of various microbes. The plant influences the nearby soil through the release/secretion of different compounds known as rhizodeposits, which mainly consist of carbohydrates, secondary metabolites organic acids, and amino acids (Ahkami et al., 2017). As a consequence, rhizosphere soils favoring the growth of microbial populations are described as mesotrophic. The rhizosphere has been subdivided into three zones; endorhizosphere (the portion of endodermis, root cortex, and apoplastic space between cells); rhizoplane (the surface of the root); and ectorhizosphere (the zone extending from rhizoplane to bulk soil) (Mcnear, 2013). The rhizosphere harbors diverse microbial groups that perform various functions and exert numerous effects on plant growth. They are involved in nutrient cycling, protecting from phytopathogens as well as under biotic and abiotic stress conditions, and some may act as plant pathogens. These microbial activities in the rhizosphere lead to changes in the composition, quality, and quantity of root exudates released by the plants, which in turn affect the microbial component (Philippot et al., 2013). This phenomenon known as rhizosphere feedback proposes that plants, through rhizodeposition, shape the microbial community composition in the rhizosphere which subsequently influences plant growth and productivity (Dessaux et al., 2016). Such a relationship suggests that the rhizosphere can be exploited and/or engineered to promote the growth, nutrient uptake, and production of plants. Schmid et al. (2018) investigated the bacterial diversity in the rhizosphere of offsprings of eight plant species that were previously grown for 11 years in the field under monoculture and mixture planting. The study revealed that the rhizosphere community structure is determined by soil plantation history and plant species identity (Schmid et al., 2018). There is ample evidence that the overall growth, productivity, and health of the plant depends upon the plant-microbe relationship (Adesemoye and Egamberdieva, 2013; Htwe et al., 2019; Masood et al., 2020). Such an intricate relationship suggests that to improve the overall health, growth, productivity, and to protect the plants from biotic and abiotic stresses, the rhizosphere can be engineered which represents an eco-friendly approach for more sustainable agriculture production.

\section{Components of RE}

Plants, microbes, and soil are three key components of the rhizosphere described in detail in Figure 1. All can be engineered (manipulated) to improve plant productivity.

The soil amendment (which has been practiced for two millennia) can influence the rhizosphere functioning for plant growth promotion. Soil amendments such as biochar, silicon (Villegas et al., 2017), zeolites (Jakkula and Wani, 2018), plant residues, coal fly ash, cattle manure, and sewage sludge have been used (Dessaux et al., 2016). Despite the recent progress in microbial ecology, soil analytical tools, and plant genetics, soil amendments remain an empirical technique providing descriptive information.

As the rhizosphere activity and functioning is shaped by the plant traits such as root architecture and root exudates, so these traits can be engineered through the genetic engineering of plants. Several plants have been engineered through breeding and gene editing techniques for the uptake of nutrients such as P, Fe, and Zn (Clemens, 2014; Wei et al., 2020), protection from diseases (Zhang T. et al., 2019) as well as the removal of heavy metals (Gunarathne et al., 2019). Although plant engineering brings favorable advantages to soil restoration, and plant growth, nutritional quality, and resistance to pathogens, but their application remain low due to the lack of social acceptance and concerns regarding human health and environmental sustainability.

\section{PLANT GROWTH PROMOTING MICROBES AS MAJOR TOOLS OF RE}

One of the most important strategies to engineer the rhizosphere is the manipulation and engineering of the microbiome. Microbes can positively influence plant growth and counteract most of the problems of modern agriculture, thus represent a promising approach for agriculture sustainability. Due to the complexity of the microbiome, there is limited ability to manage and manipulate the whole rhizosphere microbiome, however, the most direct and eco-friendly way to alter the microbiome is the inoculation of artificially multiplied microbes. Various products containing one or several species of bacteria or fungi in the form of biofertilizers have been commercially synthesized and are available for the improvement of plant growth and sustainability.

Among the rhizosphere microbiome, most of the bacteria known as plant growth-promoting rhizobacteria (PGPR) have positive interaction with the plant and promote their growth and survival, while only a few are found to be pathogenic for plants (Kumar and Dubey, 2020). These beneficial bacteria stimulate plant growth, make nutrients available to plants, suppress the growth of pathogens, and improve the soil structure, subsequently playing an essential role for sustainable crop production as shown in Figure 2. They also mineralize the organic pollutants and are used in bioremediation of polluted soils (Dessaux et al., 2016; Bibi et al., 2018).

Numerous symbiotic bacteria, termed intracellular PGPR, colonize the plant cells, produce special organs within the plant roots called nodules, and live inside 


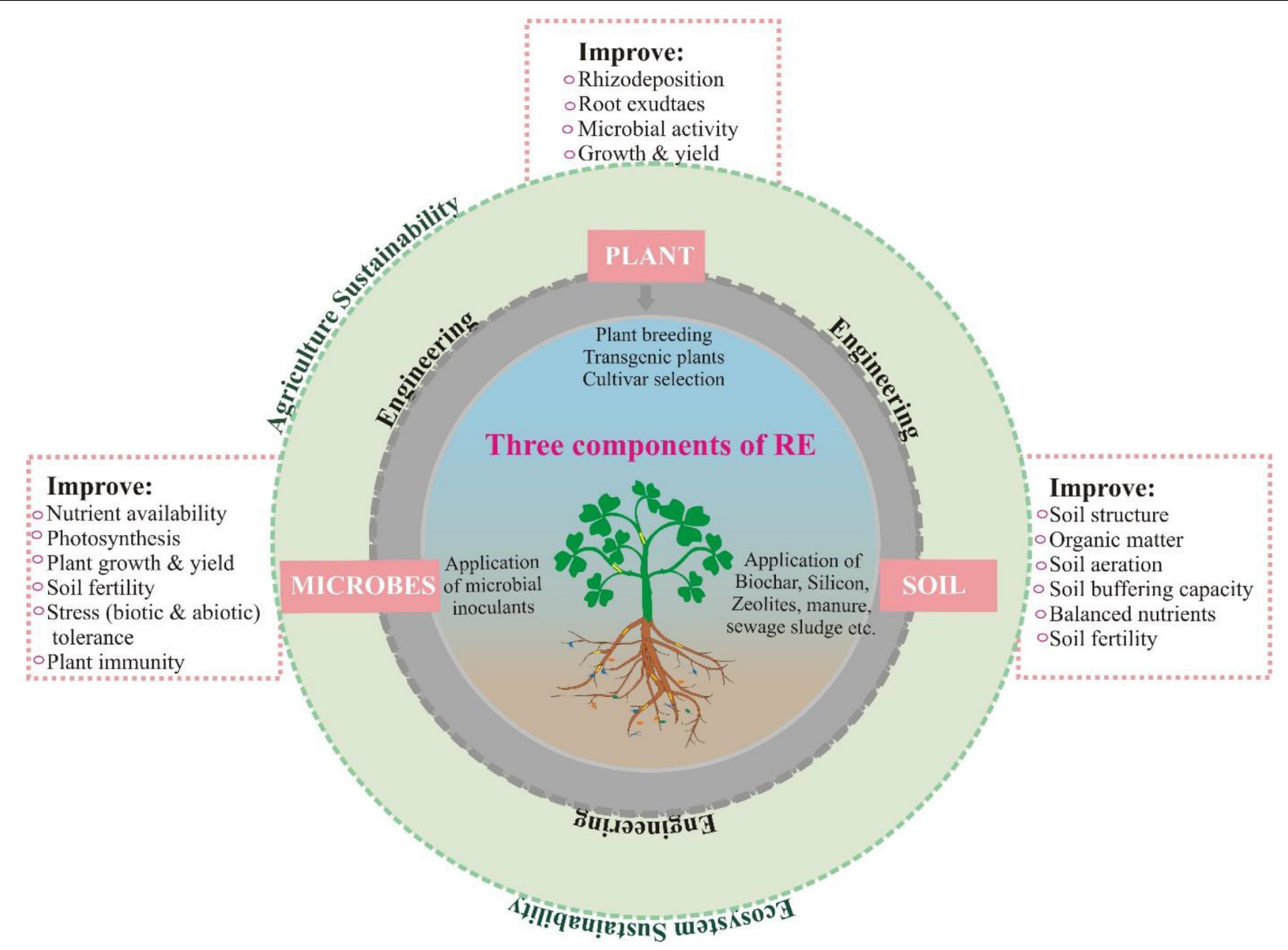

FIGURE 1 | The key components of rhizosphere engineering and intricate relationship of these components.

these nodular structures. A variety of bacteria such as Rhizobium, Sinorhizobium, Bradyrhizobium, Azorhizobium, Allorhizobium, Ochrobactrum, and Mesorhizobium are included in this group and commonly used as inocula for legumes (Imran et al., 2010; Quiza et al., 2015; Hakim et al., 2018, 2020a). Along with rhizobia, several non-rhizobial endophytes like Arthrobacter, Curtobacterium, Micromonospora, Microbacterium Mycobacterium, Acinetobacter, Agrobacterium, Blastobacter, Bosea, Devosia, Enterobacter, Herbaspirillum, Pantoea, Pseudomonas, Ralstonia, Stenotrophomonas, Bacillus, Brevibacillus, Paenibacillus, Chryseobacterium, and Sphingobacterium also colonize the interior of root nodules (Velázquez et al., 2013; De Meyer et al., 2015; Leite et al., 2017; Hakim et al., 2020b). Free-living rhizobacteria, known as extracellular PGPR (ePGPR), are present in soil and do not inhabit plant tissues. Some examples of ePGPR are Arthrobacter, Bacillus, Azospirillum, Azotobacter, Micrococcus, Pseudomonas, and Serratia (Adesemoye and Egamberdieva, 2013). Besides, actinomycetes are also a major group of microbes inhabiting the rhizosphere which display numerous beneficial traits to improve plant productivity (Muleta and Assefa, 2018). However, culturable microbes represent $1-5 \%$ of the microbes present on the earth (Kumar and Dubey, 2020). Furthermore, there is limited information about the bacterial communities inhabiting the different plant compartments such as root nodules, leaves, stems (Kumar and Dubey, 2020). As a consequence, culture-independent approaches such as metagenomics has been used to investigating the rhizosphere microbiome. This method is also used to detect the functional diversity of specific microbes in different environments. The diversity of nitrogen fixers has been evaluated through the nifH gene amplified from diverse environments including forest and agricultural soils, marine environments, estuarine sediments, microbial mats, hydrothermal vents, termite guts, and Antarctic environments (Collavino et al., 2014; Jing et al., 2015). The diversity of denitrifying microbial populations in the sediment of boreal lakes has been evaluated through pyrosequencing of nitrite and nitrous oxide reductase genes (nirK, nirS, and nosZ) (Saarenheimo et al., 2015). The morA gene-based metagenomics was used for the assessment of methanogen 


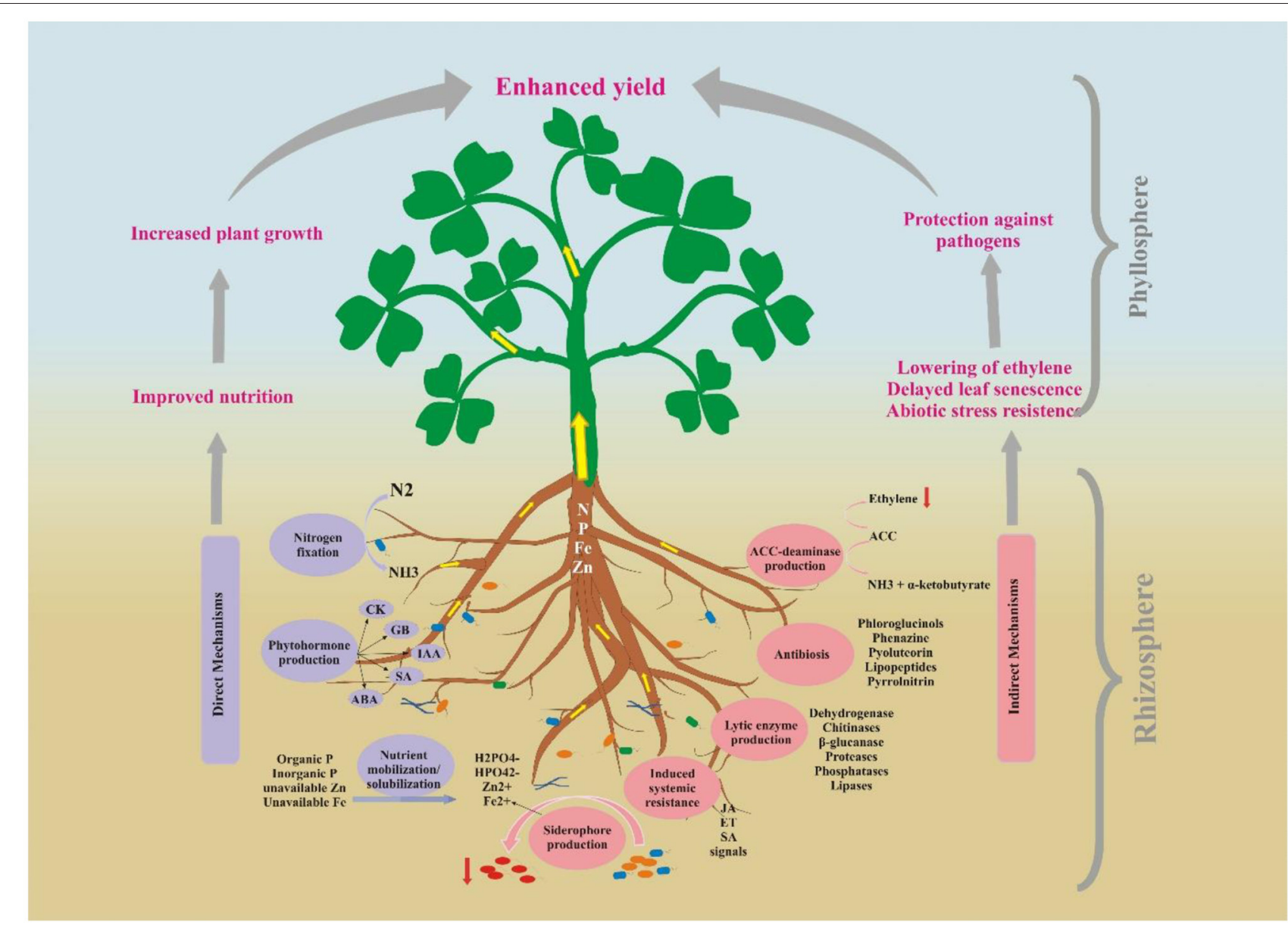

FIGURE 2 | The benefits of PGPR-mediated rhizosphere engineering to the plant growth.

diversity in anaerobic digesters (Wilkins et al., 2015). The microbiome-mediated rhizosphere engineering strategy requires culturing and inoculation of bacteria to increase the functional capacity of microbes in the rhizosphere. Bio-inoculants of Acetobacter, Azospirillum, Bacillus, Micromonospora, Paenibacillus, Enterobacter, Pseudomonas, Herbaspirillum, Serratia, Rhodococcus, and Streptomyces enhanced production in a range of crops (Martínez-Hidalgo et al., 2014; Zaheer et al., 2016; Htwe et al., 2018). Various studies revealed that plant inoculation with consortia of PGPR has a synergistic effect on the plant growth helps to alleviate abiotic and biotic stresses by producing various defense compounds. Co-inoculation of Bacillus megaterium and Paenibacillus polymyxa along with Rhizobium have shown enhanced plant biomass of Phaseolus vulgaris as compared to Rhizobium inoculation alone (Korir et al., 2017). Similarly, the application of Rhizobium and Pseudomonas increased the mung bean biomass and yield along with the improved concentration of nitrogen $(\mathrm{N})$, potassium $(\mathrm{K})$, and sodium (Na) in plants (Ahmad et al., 2012). Co-inoculation of Bradyrhizobium strain along with Streptomyces griseoflavus increased the nodulation, nitrogen fixation, and nutrients uptake of Glycine max (Htwe et al., 2018). Further, detailed studies are required to investigate the functionality and persistence of the inoculants and their potential to form an association with nearby microbes when this strategy is used to engineer the rhizosphere.

\section{How PGPR Engineer the Rhizosphere}

PGPR contain various traits which exert positive effects on plant growth through direct and indirect mechanisms. Major direct mechanisms of actions of PGPR include mobilization of nutrients $(\mathrm{P}, \mathrm{Zn}$, and $\mathrm{Fe}$ ) nitrogen fixation, and production of phytohormone. Biocontrol of pathogens by the production of ACC-deaminase, siderophores, antibiotics, lytic enzymes, induced systemic resistance, and induction of resistance against abiotic stresses are described as indirect mechanisms of action of PGPR. Figure 2 summarizes the direct and indirect growth-promoting effects exerted by PGPR on plants and the rhizosphere.

\section{Nutrient Mobilization in the Rhizosphere Phosphate solubilization}

Phosphorus $(\mathrm{P})$ is the 2nd most important macronutrient for plants that is involved in all major physiological and biochemical processes including cell division, photosynthesis, respiration, 
root system development, and biosynthesis of macromolecules (Sharma et al., 2011). It also plays a major role in stem strength, crop maturity and production, and quality improvement of many fruits, vegetables, and grain crops (Sagervanshi et al., 2012). P is one of the important constituents of nucleic acid and phospholipids. At the cellular level, the most important function of phosphorus is energy storage and transfer through ATP (Kaviyarasi et al., 2011). It helps crops to survive in harsh winter conditions and improves the quality of the produce (fruits, vegetables, grains) (Sagervanshi et al., 2012). Phosphorus deficiency leads to stunted plant growth, chlorosis, and low productivity (Malhotra et al., 2018). In severe cases, symptoms include stunting, purpling, or browning of leaves, which are more pronounced at fast growth stages i.e., young plants (Ziadi et al., 2013). It is also important for biological nitrogen fixation in legumes.

Although $\mathrm{P}$ is abundantly present in both inorganic and organic forms in the soil, but a small fraction $(0.1 \%)$ exists in the soluble (plant-available) form $\left(\mathrm{HPO}_{4}^{-2}\right.$ or $\mathrm{H}_{2} \mathrm{PO}_{4}$ ) (Sharma et al., 2013). Organic phosphorus constitutes about $20-80 \%$ of the total phosphorus pool and exists as soil humus and represent an important reservoir of immobilized P. Most of the organic P exists in the form of inositol phosphate (10$50 \%)$, sugar phosphates, phospholipids (1-5\%), nucleotides $(0.2-$ 2.5\%), phosphoprotein and phosphonates (Khan et al., 2014). The inorganic form of phosphate is produced by weathering of rock and sequestered in soil either by adsorption to the soil mineral surfaces or through precipitation (Richardson and Simpson, 2011). P is fixed by free oxides and hydroxides of aluminum and iron in acidic soil while by calcium in alkaline soils (Li et al., 2016). Due to the insufficient available phosphorus in cultivable lands, high doses of chemical phosphate fertilizers are added to the soil to support crop production. But only a small fraction of the applied fertilizer is taken up by the plant while the remaining is converted into an insoluble form; unavailable for the plant (Cabeza et al., 2019). This high accumulation causes eutrophication which is harmful to aquatic life as well as humans. The inaccessible inorganic $\mathrm{P}$ is hydrolyzed through the $\mathrm{P}$ solubilization process, while the insoluble organic P is converted to soluble form through mineralization. Several microorganisms i.e., bacteria, fungi, and actinomycetes are an integral component of the natural Pcycle and involved in the transformation of phosphate in soil. Among the total microbial population in the soil, $1-50 \%$ of bacteria and only $0.1-0.5 \%$ of fungi have the potential for $\mathrm{P}$ solubilization. They convert the insoluble inorganic phosphate to plant-available form through $\mathrm{H}^{+}$excretion and organic acid production. Different types of organic acids like acetate, citrate, lactate, ketogluconate, gluconate, succinate, malate, oxalate, etc. are produced that can form complex with cations bound to phosphate and covert the $\mathrm{P}$ into a soluble form (Kalayu, 2019). Gluconic acid and ketogluconic acids are major acids involved in P-solubilization (Alori et al., 2017). The bacteria having this ability are known as P-solubilizing bacteria (PSB). Organic acids may chelate with cations present on the mineral surface of the soil, thus blocking phosphate adsorption sites on the soil particles and subsequently increasing the phosphate availability (Bianco and Defez, 2010). Production and release of organic acids and protons by the PSB lead to a decrease in the $\mathrm{pH}$ of rhizospheric soil. Several PSBs related to genera Arthrobacter, Bacillus, Brevundimonas, Delftia, Enterobacter, Gordonia, Klebsiella, Phyllobacterium, Pseudomonas, Serratia, and Xanthomonas have been reported to solubilize P through proton excretion and organic acids production (Sharma et al., 2013; Hanif et al., 2020; Naqqash et al., 2020). Other mechanisms of inorganic P solubilization by PSB include the production of chelating agents and inorganic acids such as nitric, sulfuric, and carbonic acids (Khan et al., 2014). However, these compounds have been reported to be less effective for the release of $\mathrm{P}$ in the soil as compared to the organic acids (Alori et al., 2017). The soil available $\mathrm{P}$ was found to be increased due to these PSB, for instance, a $16 \%$ increase in soil $P$ availability has been found in the rhizosphere of wheat by inoculation with Pseudomonas (Suleman et al., 2018). Similarly, Acinetobacter and Pseudomonas strain enhanced the soil available $\mathrm{P}$ to about 3.9 and $3.11 \mathrm{mg} \mathrm{kg}^{-1}$ as compared to non-inoculated control (2.33 $\mathrm{mg} \mathrm{kg}^{-1}$ ) (Rasul et al., 2019).

The solubilization of organic $\mathrm{P}$ to soluble form is referred to as P-mineralization. Various soil microbes possess $\mathrm{P}$ mineralization ability. This process involves the liberation of different enzymes such as (i) phosphatases which are involved in the dephosphorylation of phosphor-ester or phospho anhydride bond of organic compounds, and (ii) phytases that release the $\mathrm{P}$ stored in plant materials in the form of phytate (Khan et al., 2014). The phosphatases released by the microbes can either be acid or alkaline. These phosphatases are nonspecific, possess a greater affinity for organic $\mathrm{P}$ compounds, and convert them into a soluble form. Several bacteria from the genera Aneurinibacillus, Bacillus, Burkholderia, Flavobacterium, Lysinibacillus, Pseudomonas, and Serratia exhibit phosphatase activity and improve the growth of various crops including wheat and maize (Iqbal Hussain et al., 2013; Schoebitz et al., 2013; Behera et al., 2017; Matos et al., 2017). Phytases have been detected in many bacteria such as Bacillus sp., Citrobacter braakii, Escherichia coli, Enterobacter, Pseudomonas sp. Raoultella sp. and anaerobic rumen bacteria, particularly in Megasphaera elsdenii, Mitsuokella spp. Prevotella sp. and Selenomonas ruminantium (Azeem et al., 2015). Phytase-producing Tetrathiobacter and Bacillus strains enhanced the shoot and root dry weight and thus improved the plant growth and P contents of Brassica juncea (Kumar et al., 2013).

\section{Zn-mobilization}

Zinc is an indispensable micronutrient, required in a small amount for crops to play numerous important functions in their life cycle (Hafeez et al., 2013). It is involved in various physiological and biochemical functions of plants (Kumar et al., 2019) and performs a pivotal role in DNA transcription as it is found in DNA-binding proteins. Zn-finger proteins play a central role in several developmental processes as well as responses to environmental stresses (Noguero et al., 2013). $\mathrm{Zn}$ is described as the only element found in all six enzyme classes (hydrolases, isomerases, ligases, lyases, oxidoreductases, and transferases) playing an essential role in the proper functioning of enzymes 
(Saravanan et al., 2011). It plays a vital role in the metabolism of carbohydrates, proteins, and phytohormone i.e., auxin, as well as involved in membrane integrity and reproduction, thus affecting the growth, development, vigor, maturity, and yield of the plants. The deficiency of zinc in plants manifested as a remarkable reduction in height and development of whitish brown patches that subsequently turn to necrotic spots. It also leads to chlorosis, retarded leaf and shoot growth, affect the uptake and transport of water, root development, pollen formation, and grain yield as well as causing susceptibility to heat, light, and fungal infections resulting in a major loss in crop production (Kumar et al., 2019). Zn deficiency in human results in impaired brain function, anemia, retarded growth, hypogeusia in children, anorexia, poor mental development, and several chronic diseases in humans (Liu D. et al., 2017). Zn-deficiency is prevalent in most developing countries and affected more than three billion people worldwide. Therefore, $\mathrm{Zn}$-biofortification is recommended to prevent $\mathrm{Zn}$ deficiency in humans.

FAO reports that $50 \%$ of the soils have inadequate Zinc (Shaikh and Saraf, 2017) or Zn is fixed in compounds which are unavailable to plants. In soil most of the zinc is present as sphalerite $(\mathrm{ZnS})$, zincite $(\mathrm{ZnO})$, hopeite $\left[\mathrm{Zn}_{3}\left(\mathrm{PO}_{4}\right)_{2} \cdot 4 \mathrm{H}_{2} \mathrm{O}\right]$, zinkosite $\left(\mathrm{ZnSO}_{4}\right)$, franklinite $\left(\mathrm{ZnFe}_{2} \mathrm{O}_{4}\right)$, and smithsonite $\left(\mathrm{ZnCO}_{3}\right)$ (Shaikh and Saraf, 2017). Plants can uptake zinc in the form of $\mathrm{Zn}^{2+}$ cation, but soil solution contains a minor fraction of it. The unavailability of zinc soluble form in the soil directly affects the plant growth and its grain quality and thus human health. Zinc fertilizers have been used to overcome its deficiency, but it leads to increased economic burden as well as threatened the public health and environment. Therefore, farmers are encouraged to use alternative eco-friendly approaches for sustainable agriculture.

PGPR can increase Zn-availability to plants by solubilizing complex $\mathrm{Zn}$ compounds and thus alleviate $\mathrm{Zn}$ deficiency in plants (Saravanan et al., 2011). Zinc biofertilizers containing effective zinc solubilizing bacterial strains (ZSB) help to enhance the availability of zinc and improve plant growth and development. A pioneering study in this area reported the solubilization of $\mathrm{ZnO}, \mathrm{ZnS}$, and $\mathrm{ZnCO}_{3}$ by Bacillus sp. and Pseudomonas fluorescens isolated from the garden and paddy soil (Saravanan et al., 2011). Later on, several efficient PGPR strains including Acinetobacter, Bacillus thuringiensis, Burkholderia cenocepacia, Gluconacetobacter diazotrophicus, Pseudomonas aeruginosa, P. striata, Serratia liquefaciens, and $S$. marcescens have been reported with the ability to solubilize zinc and improved the plant growth, zinc content, and yield of various crops. The Zn-solubilization mechanism is similar to the P-solubilization phenomenon where solubilization is done by acidification or chelation (Saravanan et al., 2011). ZSB produce organic acids such as acetic acid, formic acid, gluconic acid, citric acid, 2ketogluconic acid, lactic acid, malic acid, and oxalic acids in the rhizosphere subsequently acidifying the surrounding areas. These organic acids chelate with the cations bound to the zinc compound and enhance zinc solubility.

Studies have documented the mitigation of $\mathrm{Zn}$ deficiency with subsequent increase in yield through the inoculation of ZSB in rice (Vaid et al., 2014), wheat (Kamran et al., 2017), maize
(Goteti et al., 2013), mung bean (Iqbal et al., 2010), and soybean (Ramesh et al., 2014). A Rhizobium strain RL9 also showed Zn solubilization ability and improved the nodulation, dry matter, yield, leghemoglobin, and grain protein of lentil (Kumar et al., 2019).

\section{Fe-sequestering}

Iron $(\mathrm{Fe})$ one of the dominant micronutrients, plays an important role in regulating the cellular processes essential for the growth and development of plants. It is an important cofactor in enzymes, involved in photosynthesis, regulation of respiration, synthesis, and protection of DNA, and metal homeostasis (Zhang X. et al., 2019). Although iron is the fourth most abundant element on earth, its availability for plants is low, particularly in calcareous soils. At neutral and alkaline $\mathrm{pH}$, it exists in oxidized ferric $\left(\mathrm{Fe}^{3+}\right)$ form which is highly insoluble and inaccessible for plants (Kramer et al., 2019). The low uptake of Fe in plants from iron-deficient soil leads to decreased photosynthesis, chlorosis, yield, and quality of crops (Zhang X. et al., 2019). Moreover, over $30 \%$ of the world's population is severely affected by iron deficiency leading to anemia which is a nutritional disorder in humans.

Plants use different strategies to obtain this essential trace element from the environment. One most important strategy is microbe-mediated iron uptake in plants. PGPR produce low molecular weight, high-affinity ferric iron chelator, known as siderophores which enable iron acquisition through specific uptake systems. The siderophores are divided into three main groups i.e., hydroxamates, catecholates, and carboxylates depending upon the functional group used to form complexes with the ferric (Shameer and Prasad, 2018). The siderophores are strongly bound with the insoluble ferric ion $\left(\mathrm{Fe}^{3+}\right)$ through the ligands and form a soluble complex in soil. The siderophore receptors present at the cell membrane of plant roots recognize the Fe-siderophore complex and are taken up by the cell (Singh, 2020). Besides the acquisition of iron from insoluble hydroxide, siderophore can also acquire iron from ferric phosphate, ferric citrate, ferric transferring iron bound to plant flavones pigment, glycosides, and sugar (Ghosh et al., 2020). Several bacteria such as Agrobacterium tumefaciens, Azospirillum, Azotobacter, Bacillus, E. coli, Enterobacter, Mycobacterium, Neisseria gonorrhoeae, Paracoccus denitrificans, P. fluorescens, Rhizobium meliloti, Serratia, and Streptomyces, etc. have been reported to synthesize siderophores (Ghosh et al., 2020; Singh, 2020). Application of siderophore-producing bacteria have shown the improvement in growth and productivity of various crop plants such as rice (Karnwal, 2017), wheat (Gull and Hafeez, 2012), maize (Sah et al., 2017), and chickpea (Khalid et al., 2015) by increased availability of Fe. It has been reported that siderophores increased the chlorophyll contents and plant biomass along with an increase in iron concentration in sunflower under water stress conditions inoculated with Pseudomonas spp., Enterobacter spp., and Bacillus sporothernodurans (Pourbabaee et al., 2018). Furthermore, the PGPR strains Agrobacterium sp., Alcaligenes sp., Bacillus sp. Pantoea sp., and Staphylococcus sp., improved the organic acids in leaf and the Fe contents in leaf, root, and soil, as well as enhanced the activity of ferric chelate-reductase 
(FC-R) enzyme in pear grown under calcareous soil conditions (Ipek et al., 2017).

\section{Nitrogen Fixation}

Nitrogen (N) constitutes about $2 \%$ of the total dry matter of a plant and is essentially required for plant growth. Plants need $\mathrm{N}$ for the synthesis of nucleic acid, proteins, and enzymes (Bano and Iqbal, 2016). Its deficiency leads to reduced growth, yellowing of leaves, and reduced branching in legumes. The dinitrogen gas $\left(\mathrm{N}_{2}\right)$ that represents about $80 \%$ of the atmosphere is not accessible to plants. Plants can only take up soil-available in the form of ammonia and nitrates through their roots. The ammonium form is directly assimilated into amino acids and stimulates root branching to increase the surface for the uptake of nutrients as well as results in higher amino acid, chlorophyll contents, sugar, and starch. While the nitrate has to be converted into ammonium before it can be used (Beeckman et al., 2018). Nitrate improves the uptake of more nutrients through lateral root elongation and has a more direct effect on different signaling pathways (O'Brien et al., 2016). Thus, both nitrogen sources have significance for plant growth.

The process in which inert $\mathrm{N}_{2}$ gas is converted to a metabolically tractable form in the soil is called nitrogen fixation. The manufacturing of synthetic $\mathrm{N}$ fertilizer through the industrial process is an expensive process as it needs six times more energy than required to produce either phosphorus $(\mathrm{P})$ or potassium (K) fertilizers. During the last 45 years, the demand for nitrogen fertilizers has enhanced from 12 to $107 \mathrm{Tg}_{\text {year }}{ }^{-1}$ and is expected to increase to $111.5 \mathrm{Tg} \mathrm{year}^{-1}$ in the year 2022 (FAO, 2019). On the other hand, the yield has been significantly decreased due to the poverty of farmers who are unable to apply costly synthetic fertilizer demands to the crops.

Biological Nitrogen Fixation (BNF), the process in which elemental nitrogen is converted to ammonia by bacteria is an alternative source of $\mathrm{N}$ for plants. These nitrogen-fixing bacteria are ubiquitous in nature and function under different environmental conditions. The input of nitrogen into soil through BNF ranges from 0 to $60 \mathrm{~kg} \mathrm{ha}^{-1}$ year $^{-1}$ (Reghuvaran et al., 2012) with an estimated contribution of 175 million metric tons annually covering $70 \%$ of all annual fixed nitrogen on the Earth (Lodewyckx et al., 2002). There are generally two categories of nitrogen-fixing microorganisms; (a) symbiotic and (b) non-symbiotic bacteria. The most common symbiotic $\mathrm{N}_{2}$ fixing bacteria able to infect legumes include Rhizobium, Bradyrhizobium, Ensifer, Azorhizobium, and Mesorhizobium, etc. while Frankia nodulates non-leguminous trees and shrubs. These rhizobia infect the root hair, stimulate root hair curling, and leads to the formation of infection thread. The bacterial cells enter the plant cells through infection threads and result in the formation of a nodule wherein the rhizobia reside and fix nitrogen for plants (Andrews and Andrews, 2017). The non-symbiotic diazotrophic bacteria include Arthrobacter, Azoarcus, Azospirillum, Azotobacter, Enterobacter, Mitsuaria, Pseudomonas, etc. which fix atmospheric nitrogen in the freeliving form (Gupta et al., 2015). The nitrogen-fixing bacteria improve the soil $\mathrm{NH}_{4}^{+}$concentrations, rhizobacterial population levels, soil nitrogenase activity as well as the growth and $\mathrm{N}$ uptake in plants (Masood et al., 2020). Similarly, the application of biofertilizer produced from rhizobia (Bradyrhizobium strains) and free-living PGPR (Streptomyces griseoflavus) improved the growth and yield of several plants such as mung bean, cowpea, and soybean (Htwe et al., 2019).

BNF is carried out by a nitrogenase complex that consists of two components (i) dinitrogenase reductase (an iron protein) which provides high reducing power electrons and (ii) dinitrogenase which uses the electrons to reduce nitrogen to ammonia and has a metal cofactor. There are three different forms of nitrogenase classified based on metal cofactor. (a) Mo-nitrogenase whose cofactor contains molybdenum, (b) Vnitrogenase which contains a prosthetic group with vanadium, and (c) Fe-nitrogenase contains only iron (Ahemad and Kibret, 2014). Symbiotic as well as free-living diazotrophs use nif genes for the fixation which include structural genes that are involved in the biosynthesis of iron-molybdenum cofactor, iron protein activation, donation of electrons, and regulatory genes required for the functioning of the enzyme. The nif genes are found in the form of 20-24 kb cluster with seven operons that encode 20 different proteins in diazotrophs (Glick, 2012). The amino acid sequence of nifH is highly conserved and generally used to study the evolution of nitrogen-fixing bacteria. It is also widely used to analyze the diversity of diazotrophs in the soil (Gaby et al., 2018). Investigation of diazotrophs community structure using metagenomics based on 185 nitrogenase sequences identified a key group of diazotrophs including Anaeromyxobacter, Azoarcus, Bradyrhizobium, Frankia, Geobacter, Nostoc, and Pelobacter based on nifH phylogeny (Nash et al., 2018). In the Amazone rainforest, a shift in community composition and abundance of diazotrophs in response to deforestation (forest-to-pasture conversion) was evaluated using sequence analysis of the marker gene nifH (Mirza et al., 2014). This change in community composition of diazotrophs is a consequence of higher demand for $\mathrm{N}$ of pasture plant communities.

Besides the ability of PGPR to fix $\mathrm{N}_{2}$ to ammonia, they also have a great impact on nitrogen nutrition of plant by increasing the uptake of nitrate $\left(\mathrm{NO}_{3}^{-}\right)$(Beeckman et al., 2018). The PGPR can increase the uptake of nitrate directly by stimulating $\mathrm{NO}_{3}^{-}$ transport systems or indirectly as a consequence of stimulated lateral root development. It has been reported that two putative nitrate transporter genes i.e., NRT2.5 and NRT2.6 appeared to be strongly upregulated in response to the inoculation of Phyllobacterium brassicacearum in Arabidopsis thaliana (Kechid et al., 2013). Similarly, the nitrate transporter genes were found to be upregulated in rice roots during interactions with Azospirillum brasilense (Thomas et al., 2019). Calvo et al. (2019) reported that inoculation of PGPR consortia of Bacillus, Lysinibacillus, and Paenibacillus strains upregulated the four ammonium and five nitrate uptake genes along with a significant increase in plant biomass, chlorophyll content, and nutrient uptake in A. thaliana (Calvo et al., 2019).

Although, nitrate is a plant-available form, in the soil it is highly prone to leaching due to no adherence with soil particles, and thus becomes inaccessible for plants. Therefore, ammonium is the more efficient form of nitrogen under field conditions, but it is also oxidized to nitrate. Plants can 
produce nitrification-inhibiting compounds which are known as biological nitrification inhibitors (BNIs) (Beeckman et al., 2018). The exposure of pasture grasses, sorghum, and wheat to more $\mathrm{NH}_{4}^{+}$showed an increase in the synthesis and release of BNIs. Application of BNI promoted the root branching along with increased nutrient uptake providing a dual strategy to enhance fertilizer efficiencies (Liu et al., 2016b).

\section{Phytohormone Production}

Phytohormones influence the physiological functions of plants at very low concentrations as chemical messengers. The phytohormones are key determinants of plant behavior and play a leading role in various physiological and developmental processes. Traditionally, plant hormones have been divided into five different classes: auxin, cytokinins, gibberellins, abscisic acid, and ethylene (Oleńska et al., 2020). Besides, several phytohormones such as jasmonate, brassinosteroids, and salicylic acid also play significant roles in plant growth and development particularly under biotic and abiotic stress conditions (Wong et al., 2015; Kang et al., 2016). A wide range of rhizosphere inhabiting bacteria can produce phytohormone for facilitating plant growth and development. The phytohormones produced by plants and rhizobacteria are involved in all the communication in plant cells (Maheshwari et al., 2015).

\section{Auxin}

Auxin is the most imperative phytohormone which controls nearly all aspects of plant development. Indole-acetic acid (IAA) is the most common, well-characterized auxin produced by bacteria and plants. In plants, IAA plays an important role in apical dominance, division, and cell differentiation, seed germination, and the development of roots. It also contributes to processes like photosynthesis, biosynthesis of metabolites, and stress resistance (Maheshwari et al., 2015). Bacteria-produced IAA promotes the root length and surface area for enhanced uptake of nutrients and water. The majority of the microbes (>80\%) inhabiting the rhizosphere are capable of synthesizing and releasing auxin (Oleńska et al., 2020). Tryptophan has been identified as the main precursor of auxin biosynthesis. There are three main pathways involved in IAA synthesis by microbes: (1) Indole acetic acid synthesis via intermediates indole-3pyruvic acid and indole-3-acetic aldehyde, is found in bacterial genera like Erwinia, Agrobacterium, Pseudomonas, Azospirillum, Bradyrhizobium, Enterobacter, Klebsiella, and Rhizobium. (2) IAA biosynthesis via tryptamine and indole-3-acetic aldehyde which has been reported in Azospirillum and Pseudomonas. (3) The IAA synthesis via indole-3-acetamide (IAM) formation, which operates in Agrobacterium, Erwinia, and Pseudomonas strains (Tahir and Sarwar, 2013). The indole-3-acetamide (IAM) pathway commonly found in bacteria, involves the conversion of tryptophan to indole-3-acetamide by the enzyme tryptophan2- monooxygenase (IaaM), and then IAM is converted to IAA by the enzyme IAM hydrolase (iaaH). The two genes involved in the IAM pathway (iaaM and iaaH) have been identified in Agrobacterium, Bradyrhizobium, Pantoea, Pseudomonas, and Rhizobium strains. Genes involved in IAM pathway have been localized on the chromosome (Pseudomonas spp.) as well as on plasmids (e.g., Pantoea agglomerans). These auxin-producing PGPR modulate the plant response as reported through cucumber-Bacillus amyloliquefaciens strain SQR9 system, which showed that inoculation of Bacillus amyloliquefaciens leads to the high amount of tryptophan secretion through roots of cucumber, subsequently increasing the IAA synthesis by bacteria inhabiting the rhizosphere (Liu et al., 2016a). Several studies reported the improvement in root formation, growth, and yield of various crops through auxin-producing PGPR (Ali et al., 2014; Imran et al., 2015; Majeed et al., 2015). Moreover, bacteriaderived auxins might be involve in the mitigation of deleterious effects of various abiotic stresses, like salinity, drought, and soil pollution (Kudoyarova et al., 2019). The application of auxin producing Bacillus thuringiensis, B. amyloliquefaciens, $B$. simplex, Enterobacter aerogenes, Moraxella pluranimalium, and Pseudomonas stutzeri strains showed positive effect growth and yield parameters of wheat grown under drought condition and suggested to be used for rhizosphere engineering in drylands (Raheem et al., 2018).

\section{Cytokinin}

Cytokinins (CK) are important signaling molecules that are involved in the regulation of plant growth and development. This plant hormone plays a crucial role in various physiological and developmental processes including apical dominance, seed germination, nodule formation, flower and fruit development, root elongation, vascular development, and plant-pathogen-interactions (Osugi and Sakakibara, 2015). The bacterial genera such as Bacillus, Escherichia, Agrobacterium, Methylobacterium, Proteus, Pseudomonas, and Klebsiella can produce cytokinins (Maheshwari et al., 2015). The pathway of cytokinin biosynthesis involves the formation of N6-isopentenyl adenosine monophosphate from adenosine monophosphate (AMP) and dimethylallyl pyrophosphate (DMAPP). While in bacteria, the synthesis involves the transfer of isopentenyl moiety from hydroxyl dimethyl butenyl diphosphate (HMBDP) to AMP (Wong et al., 2015). Bacteria synthesize and release cytokinin in the rhizosphere, subsequently increasing the contents of cytokinin in the soil solution and growing plants which leads to stimulation of the plant growth. Furthermore, these PGPR mitigate the effect of stresses as cytokinin-producing Bacillus subtilis alleviated the drought stress and increased the plant growth of Platycladus orientalis (Liu et al., 2013). The bacterial cytokinin also reported to be involved in regulating the defense system of the host plant against pathogens. For instance, cytokinins produced by $P$. fluorescens efficiently controlled the $P$. syringae infection, maintained the tissue integrity and yield in Arabidopsis (Großkinsky et al., 2016).

\section{Gibberellin}

Gibberellins (GAs) are plant hormones that are involved in nearly all stages of plant growth and development, including embryogenesis, stem elongation, flowering, leaf expansion, and ripening of fruits (Binenbaum et al., 2018). Natural GAs are the conjugates of $\beta$-D-glucose, but they are also found in free and bound states. Like auxins and cytokinin, bacteria also possess the ability to synthesize GAs. Among bacteria, 
the characterization of gibberellins (GA1, GA4, GA9, and GA20) was first reported in Rhizobium meliloti (Atzorn et al., 1988). Since then, several bacterial genera such as Acetobacter, Azospirillum, Herbaspirillum, Bacillus, and Pseudomonas have been reported for GAs production (Maheshwari et al., 2015). The function of GAs in bacteria is still not known but they might act as signaling molecules toward plants. However, the stimulation of plant growth and yield is evident through various studies. For instance, inoculation of Solanum lycopersicum with GAs producing Promicro monospora strain upregulated the GA biosynthesis pathway while downregulated the synthesis of abscisic acid in the plant (Kang et al., 2012). A rhizobacterium Leifsonia soli showed GAs production ability and stimulated the growth of cucumber, radish, and tomato plants (Kang et al., 2014a). Another GA producing Leifsoniaxyli strain maintained the growth of Solanum lycopersicum under copper $(\mathrm{Cu})$ stress condition by modulating the endogenous polyphenol, flavonoid, and amino acids (arginine, proline, glycine, phenylalanine, threonine, and glutamic acid) reduced superoxide dismutase activity (Kang et al., 2017). The role of GAs in the alleviation of temperature stress has also been reported. Serratia nematodiphila enhanced the endohenous GA4 and ABA while reduced the salicylic acid and jasmonic acid contents of the host plant to mitigate the deleterious effects of low temperature on Capsicum annuum (Kang et al., 2015). Similarly, Bacillus tequilensis improved the plant biomass of the soybean by producing GA1, GA3, GA5, GA8, GA19, GA24, and GA53 under the hightemperature stress (Kang et al., 2019b).

\section{Biocontrol of Plant Pathogens}

The phytopathogenic microorganisms and abiotic stresses are threatening global crop production. The vigorous application of pesticides and fungicides to prevent pathogenesis and growth of pathogenic microorganisms has degraded and contaminated the soil quality (Gopalakrishnan et al., 2015). The application of PGPR is an effective and environmentally safe strategy to achieve sustainable plant growth and soil fertility. This approach encourages the manipulation of wide-ranging PGPR to suppress pathogen growth. The use of biocontrol agents as pesticides has reduced the demand for agrochemicals because they use various mechanisms to kill the phytopahtogens such as ACC-deaminase activity, production siderophores, lytic enzymes, quorum sensing (QS), induced systemic resistance (ISR) etc. (Torres-Cortés et al., 2018; Ali et al., 2020; Chen et al., 2020; Rodríguez et al., 2020).

In recent years, biocontrol of phytopathogenic microbes through other microorganisms has emerged for sustainable agriculture (Karthika et al., 2020). The antagonistic characteristics of PGPR play a key role in managing plant diseases while improving soil fertility and crop production (Liu Y. et al., 2017). The mechanisms utilized by PGPR for biocontrol are as follows.

\section{Production of ACC-deaminase}

In response to pathogenic infection, plants accumulate several hormones, including ethylene, which activates secondary stresses like root hair curling, oxidative stress, and nutrient deficiency, leading to decreased metabolism, growth rate, crop productivity, development, and eventually results in plant death (Premachandra et al., 2016). PGPR mitigate the harmful effects of phytopathogens on the development and growth by interacting with host plants.

The ability of soil microbes for producing ACC deaminase enzyme is the key feature that decreases the level of pathogeninduced ethylene and its subsequent deleterious effects. A variety of microorganisms are reported that can produce ACC-deaminase and help plants in overcoming the stressed condition such as Bacillus, Pseudomonas, Azospirillum lipoferum, Rhizobium, and Ralstonia solanacearum (Ali et al., 2020). During stress, the concentration of ACC increases within the roots of the plant. The microbial populations producing ACC deaminase hydrolyses the exuded ACC into ammonia and $\alpha$-ketobutyrate, which ultimately reduces the stress induced by ethylene and its related growth inhibition (Saraf et al., 2010).

These rhizospheric microbes also possess the potential to improve the efflux of ACC from roots. The plant secretes a significant quantity of ACC for maintaining equilibrium both within and outside the roots. Consequently, the growth of ACCdeaminase producing beneficial microbes in the rhizosphere is accelerated, thus reducing the concentration of ACC in the roots of the plant and resulting in the decrease in ethylene production and improved plant growth (Nadeem et al., 2010; Gamalero and Glick, 2015). Furthermore, the microorganisms use this secreted ACC as the source of nitrogen. The activity of microbial ACC deaminase converts it again into ammonia \& $\alpha$-ketobutyrate, which controls the ethylene production. Thus, PGPR having the potential to produce ACC deaminase serves as a soldier for the detrimental impact of ethylene and acts as biocontrol agents against different pathogenic attacks such as Botrytis cinerea, Rhizoctonia solani, Fusarium oxysporum, Xanthomonas oryzae, Pythium ultimum, Phytophthora sp., and Sclerotium rolfsii etc. However, it is crucial to decipher the precise mechanism of ACC deaminase activity. Such ACC deaminase producing-PGPR is fascinating scientists to manipulate them at the molecular level and thus establish a vision for a more specific use.

\section{Production of siderophores}

In soil, iron is present in an abundant amount, but it is not frequently accessible for soil microorganisms or plants. The oxidized form $\left(\mathrm{Fe}^{3+}\right)$ reacts to produce hydroxides and insoluble oxides like $\mathrm{Fe}(\mathrm{OH})_{3}$ that are not easily used by both microorganisms and the plants (Mehnaz, 2013). To solve this issue, PGPR produces siderophores. Siderophores are iron-chelating, high affinity low molecular weight $(<1 \mathrm{kDa})$ compounds having the potential to provide iron to the cell or tissues of a plant (Hider and Kong, 2010). They enhance plant development and growth by improving the chances of iron availability in the rhizospheric region (Subramanium and Sundaram, 2020).

The siderophores reduces pathogenic microbes by creating iron competition in the rhizospheric region (Reed et al., 2015) and improves plant growth. PGPR-synthesized siderophores show a high affinity for rhizospheric $\mathrm{Fe}^{3+}$ and retain almost all of the free iron, increasing plant uptake of iron and inhibiting the growth of pathogenic microbiota. Bacterial siderophores are 
divided into four major classes (phenol catecholate, carboxylate, pyoverdines, and hydroxamates) depending on their ligands types, iron-directing functional groups, and structural features. Siderophores producing rhizobacteria colonize plant roots and eliminates all other microflora from this natural habitat. During extremely competitive circumstances, the acquisition of iron through siderophores determines the competition outcomes for various carbon sources available as the consequence of rhizodeposition or root exudation. In green gram, Pseudomonas sp. produced siderophores improved plant growth and inhibited disease progression (Sahu and Sindhu, 2011). Pseudomonas aeruginosa and Pseudomonas fluorescens produces pyoverdine and pyochelin form of siderophores. These microorganismproduced siderophores increase the uptake of $\mathrm{Fe}$ and inhibit the growth and development of pathogenic microbes due to competition for iron scavenging (Shen et al., 2013). Studies have reported several siderophores producing rhizobacteria such as Klebsiella, Bacillus, Bradyrhizobium, Streptomyces, Serratia, and Rhizobium (Mustafa et al., 2019). Many studies related to the research of PGPR have focused mainly on the potential of PGPR to produce metabolites and siderophores that lead to antibiosis (Maksimov et al., 2011).

\section{Antibiosis}

One of the most studied and powerful mechanisms against pathogenic microbes is antibiotic production by rhizobacterial strains. Antibiotic production is an extremely efficient mechanism of rhizobacteria for inhibiting pathogenic infections in various plants (Islam et al., 2016). Studies reported six different groups of antibiotics including phloroglucinols, phenazines, pyoluteorin, cyclic lipopeptides, and pyrrolnitrin. All these antibiotics are hydrogen cyanide, volatile, and diffusible, mostly associated with the biological control of various root infections. Lipopeptide bio-surfactants have been investigated in the biological control of various pathogenic microbes synthesized by Bacillus and Pseudomonas species (Ali et al., 2014, 2020). These bio-surfactants are potentially useful for competitive interactions against organisms such as fungi, bacteria, oomycetes, nematodes, and protozoa. Stenotrophomonas, Streptomyces, and Bacillus sp. produce different antimicrobial compounds like kanosamine, zwittermicin A, and oligomycin A, and xanthobaccin that inhibit the growth of phytopathogens on a large scale (Liu et al., 2018a).

One of the extensively studied and efficient antibiotic is 2,4-Diacetylphloroglucinol (DAPG), mainly synthesized by Pseudomonads. DAPG damages membrane and inhibit zoospores formation of Pythium sp. and also biocontrol bacterial canker disease of tomato plants (Bhattacharyya and Jha, 2012; Lanteigne et al., 2012). Pseudomonads also produce phenazine antibiotic which has redox activity having the potential to suppress phytopathogens, including Gaeumannomyces graminis and Fusarium oxysporum. Bacillus sp. produces several antibiotics such as polymyxin, circulin, and colistin that are vibrant and effective against phytopathogens (Maksimov et al., 2011; Liu et al., 2018a). Excessive application of antibioticproducing PGPR for growth promotion and biocontrol of pathogenic microbes has developed the ISR mechanism in several phytopathogens causing resistance against specific antibiotics because of the increased dependency of these strains. Different studies exploited specific biocontrol isolates that produce several antibiotics to avoid this kind of popularity.

\section{Lytic enzyme production}

Lytic enzyme secretion and production are the essential characteristics of biological control agents in preventing the development of pathogenic microbes (Xie et al., 2016). The mechanism of action of lytic enzymes is to disrupt the structural stability and integrity of cell walls of target pathogens (Budi et al., 2000; Tariq et al., 2017). PGPR produces different lytic enzymes such as dehydrogenase, chitinases, $\beta$-glucanase, proteases, phosphatases, lipases (Lanteigne et al., 2012; Joshi et al., 2015). PGPR through the action of these lytic enzymes play a significant role plant growth mainly by protecting plants against several pathogenic fungi such as Sclerotium rolfsii, Botrytis cinerea, Fusarium oxysporum, Pythium ultimum, Phytophthora sp., and Rhizoctonia solani (Yadav et al., 2016; Yasmin et al., 2016; Chen et al., 2020).

Studies reported the antifungal and chitinolytic actions of Serratia marcescens to inhibit pathogenic fungi such as Fusarium oxysporum and Rhizoctonia solani (Karthika et al., 2020). The application of Serratia marcescens on mycelia of pathogenic fungi inhibits fungal growth by hyphae curling, rupture of hyphae tip, and partial hyphae swelling. Streptomyces sp. and Paenibacillus strains produce cellulase and $\beta$-1,3-glucanase that cause degradation of pathogenic fungi cell walls, including Sclerotinia sclerotiorum and Fusarium oxysporum (Mun et al., 2020). Moreover, Bacillus cereus and Bacillus cepacia produce amylase, $\beta$-1,3-glucanase, cellulase, protease, xylanase, and lipase, which ruptures the cell walls of several soil-borne pathogenic microbes (Karthika et al., 2020).

\section{Induced systemic resistance}

Induced resistance is the physiological state of improved defensive ability elicited due to particular environmental stimuli and leads to strengthen and stimulate the innate defense system of the plant against subsequent pathogenic attacks. Bio-priming the plants using PGPR induce systemic resistance to a wide range of plant pathogens (Naznin et al., 2013). In plants, plant-growthpromoting fungi, and bacteria in their rhizosphere play a role in triggering ISR (Pieterse et al., 2014). Beneficial microbes that elicit ISR can suppress the immune response in roots locally. The exudation pattern in roots are altered due to the pathogen attack that in turn employs some selective microbiota for ISR induction (Berendsen et al., 2018; Chialva et al., 2018). For example, in tomato plants, the heterogeneous communities of microorganisms residing in the endosphere and episphere are involved in the modulation of phenylpropanoid metabolism that results in fortification of the cell wall and provides protection against Fusarium oxysporum f. sp. Lycopersici (Cha et al., 2016). This fortification of the cell wall is not only involved in the protection of plants against biotic stress but also the abiotic challenges like saline conditions, suggesting cross-talk between immunity and stress tolerance in plants (Kesten et al., 2019). In ISR, ethylene and jasmonate signaling is involved, both of these hormones play a significant role in enhancing the defense 
response of plants against a wide variety of phytopathogens (Bukhat et al., 2020).

The recruitment of plant defense and jasmonate signaling modulated due to different microbial communities in the rhizosphere also affects the herbivory of insects above the ground (Yuan et al., 2018). Several bacterial components are involved in inducing ISR such as 2, 3-butanediol, 2,4diacetylphloroglucinol, LPS, acetoin, cyclic lipopeptides, homoserine lactones, siderophores, and flagella (Torres-Cortés et al., 2018). Rhizobacteria mediated ISR induction in plants stimulates the release of some antimicrobial components such as benzoxazinoids and coumarin, which further increase the induction of ISR triggering strains ( $\mathrm{Hu}$ et al., 2018; Stringlis et al., 2018). Thus, the immune responses of the plant can be engineered to recruit microbes for providing plant resilience over thousands of generations.

\section{Rhizosphere Manipulation Through Quorum Sensing Signals}

Another effective agricultural approach is the intervention of QS systems in phytopathogens or biocontrol agents. QS is the inter-cellular communication mechanism in which microbial gene expression is coupled with the concentration of bacterial cells, is regulated through the diffusion of particular signaling components such as AHLs (Awan et al., 2011). This mechanism controls the expression of various phenotypic traits, and most of them are reported to be involved in the microbial pathogenesis of several economically significant agricultural pathogens (Liu et al., 2018b). For example, QS regulates various phenotypes in P. atrosepticum, Pectobacterium carotovorum, Ochrobactrum, Agrobacterium tumefaciens, Pseudomonas syringae, Ralstonia solanacearum, Dickeyasolani, and Erwinia amylovora (Imran et al., 2014). The interruption of this sensing system is another interesting approach in agriculture to combat the pathogenicity of pathogenic strains (Grandclément et al., 2016).

Quorum quenching (QQ) is a well-known interrupting strategy of a sensing system that is involved in the enzymatic hydrolysis or/degradation of signaling molecules (AHLs). Oxidoreductases, lactonases, and acylases enzymes are involved in the modification and the degradation of AHLs (Fetzner, 2015). Studies showed that this approach produces promising results in decreasing the pathogenicity of many phytopathogens (Chane et al., 2019; Rodríguez et al., 2020; Ye et al., 2020). Instead of killing or suppressing the growth of infectious agents by antibiotics, QS-mediated defense decreases the virulence and infection without compromising the growth of bacterial pathogens (Defoirdt, 2018; Torres et al., 2019; Rodríguez et al., 2020; Ye et al., 2020). This strategy neither disrupts the essential genes of microbes nor results in resistance development; thus this approach is more efficient in the long term as compared to antibiotics, though further studies are needed to confirm this claim (Bjarnsholt et al., 2010; Defoirdt, 2018). Several studies have reported resistance development against QS interference, and they also proposed that this QS interfering strategy might be less likely to transfer resistance in other microorganisms (GarcíaContreras et al., 2016). Remarkably, some QS bacterial strains were isolated from the aquatic environment (Romero et al.,
2012), while some are indigenous isolates of plants but their effect on growth and other parameters of plants is still not expored.

\section{Rhizosphere Intervention Against Abiotic Stress}

Various studies have also reported rhizobacteria mediated tolerance in plants against various abiotic stresses (Rajput et al., 2018; Asghari et al., 2020; Khan et al., 2020). However, the tolerance levels depend on the ability of these soil microbes to stimulate plant systems for expressing stressresponsive EPS, transcription factors, scavenging of ROS species, proline synthesis, and biomass stabilization (Habib et al., 2016; Chatterjee et al., 2020; Mukhtar et al., 2020). Understanding and exploration of these pathways help in better utilization of these microorganisms to alleviate different abiotic stresses. Table 1 summarizes some of the studies published on the induction of biotic or abiotic stress tolerance by PGPR inoculation. The induction of abiotic stress tolerance is discussed in the sections below.

\section{Drought}

Studies proposed that drought-tolerant rhizobacterial strains enhance plant development and growth during water deficit conditions. PGPR exhibit various tolerance and adaptation mechanisms to overcome reduced water potential, including thickening of walls, maintaining dormant stage, osmolyte accumulation, spore formation, and EPS production (Kour et al., 2019; Asghari et al., 2020). Besides supplying water content, PGPR also provides an optimum environment and nutrition for the persistent growth of plants (Kang et al., 2014b; Staudinger et al., 2016). The possible PGPR mechanisms involved in inducing drought tolerance include the production of phytohormones (IAA, ABA, and cytokinins), ACC deaminase activity, ISR, and EPS. The application of PGPR during drought stress produces IAA, which regulates shoot growth, cell division, differentiation of lateral and adventitious roots, and vascular tissues (Khan N. et al., 2019). Seed priming or co-inoculation with rhizobacterial strains triggers $\mathrm{ABA}$ production, which improves the molecular and physiological characteristics of plants by regulating drought stress-related transcription factors and hydraulic conductivity of roots to induce tolerance in a water deficit environment (Jiang et al., 2013). Azospirillum brasilense improved the negative effects of drought stress in Arabidopsis thaliana due to the increased production of ABA (Cohen et al., 2015).

In drought stress, accumulation of proline, trehalose, and glycine betaine helps bacteria to retain their membrane permeability, integrity, and functional proteins (Asghari et al., 2020). Plant biomass, nutrient uptake, growth, survival, and relative water content are improved after inoculation with drought-tolerant microbiota (Dai et al., 2019). In Trifolium, co-inoculation with $P$. putida and B. thuringiensis accumulates proline content, resulting in reduced stromal conductance and electrolyte leakage (Ortiz et al., 2015). The inoculation of beneficial microbes reduces the activity of antioxidants while increasing the production of sugar and free amino acids for stimulating abiotic stress tolerance (Vardharajula et al., 2011). Drought-tolerant rhizobacterial 
TABLE 1 | Role of rhizosphere engineering with PGPR on plant growth and stress tolerance.

\begin{tabular}{|c|c|c|c|c|}
\hline Rhizosphere/Plant host & Microbes used & \multicolumn{2}{|l|}{ Effect on plant/soil } & References \\
\hline \multicolumn{5}{|c|}{ Growth stimulation under normal conditions in rhizosphere } \\
\hline Wheat & $\begin{array}{l}\text { Enterobacter sp., A. chlorophenolicus, S. } \\
\text { marcescens, B. megaterium }\end{array}$ & \multicolumn{2}{|c|}{$\begin{array}{l}\text { P-solubilization, IAA, HCN, N-fixation, } \\
\text { Gibberellin, Siderophores }\end{array}$} & Kumar et al., 2015 \\
\hline Potato & Azospirillum sp. & \multicolumn{2}{|l|}{$\mathrm{N}$-fixation, IAA production } & Naqqash et al., 2016 \\
\hline Soybean & Bacillus cereus & \multicolumn{2}{|c|}{$\begin{array}{l}\text { Sideophore, IAA, P-solubilization, } \\
\text { EPS }\end{array}$} & Arif et al., 2017 \\
\hline Tomato & $\begin{array}{l}\text { Bacillus pumilus, Bacillus } \\
\text { amyloliquefaciens }\end{array}$ & \multicolumn{2}{|c|}{$\begin{array}{l}\text { HCN, Siderophore, N-fixation, IAA, } \\
\text { P-solubilization }\end{array}$} & Xiaohui et al., 2017 \\
\hline Potato & Brevundimonas spp. & \multicolumn{2}{|l|}{ P-solubilization, $\mathrm{N}$-fixation } & Naqqash et al., 2020 \\
\hline $\begin{array}{l}\text { Potato, Rice, wheat, maize, } \\
\text { soybean }\end{array}$ & Serratia spp. & \multicolumn{2}{|c|}{$\begin{array}{l}\text { AHLs, IAA production, Phytase } \\
\text { activity }\end{array}$} & Hanif et al., 2020 \\
\hline Maize & $\begin{array}{l}\text { Achromobacter xylosoxidans, Azospirillum } \\
\text { brasilense, Bacillus subtilis, Bacillus } \\
\text { megaterium, Pseudomonas stutzeri, } \\
\text { Rhodococcus rhodochrous }\end{array}$ & \multicolumn{2}{|c|}{$\begin{array}{l}\text { IAA production, P solubilization, Zn } \\
\text { solubilization }\end{array}$} & $\begin{array}{l}\text { Goteti et al., 2013; Qaisrani } \\
\text { et al., 2014; Zahid, } 2015\end{array}$ \\
\hline Chickpea & $\begin{array}{l}\text { Mesorhizobium ciceri, Ochrobactrum } \\
\text { ciceri, Serratia marcescens }\end{array}$ & \multicolumn{2}{|c|}{$\begin{array}{l}\text { P solubilization, IAA production, } \\
\text { Nitrogen fixation }\end{array}$} & $\begin{array}{l}\text { Imran et al., 2015; Zaheer } \\
\text { et al., } 2016\end{array}$ \\
\hline Cotton & Bacillus amyloliquefaciens, Bacillus spp. & \multicolumn{2}{|c|}{$\begin{array}{l}\text { Production of phytohormones, } \\
\mathrm{N} \text {-fixation, } \mathrm{P} \text { solubilization, and } \\
\text { antibiotic activity }\end{array}$} & Fahimi et al., 2014 \\
\hline Mungbean & $\begin{array}{l}\text { Rhizobium, Bradyrhizobium, Bacillus } \\
\text { cereus, B. drentensis, B. pumilus, B. } \\
\text { subtilis, Enterobacter cloacae, } \\
\text { Pseudomonas putida, Ochrobactrum }\end{array}$ & \multicolumn{2}{|c|}{$\begin{array}{l}\mathrm{N} \text {-fixation, } \mathrm{P} \text { solubilization, IAA } \\
\text { production, Siderophore } \\
\text { production,ACC-deaminase activity }\end{array}$} & $\begin{array}{l}\text { Akhtar and Ali, 2011; Tariq } \\
\text { et al., 2012; Mahmood } \\
\text { et al., } 2016\end{array}$ \\
\hline \multirow[t]{2}{*}{ Tomato } & P. fluorescens & \multirow[t]{2}{*}{ Ralstonia solanacearum } & Antibiosis activity & Seleim et al., 2011 \\
\hline & Bacillus velezensis & & Lipopeptides production & Chen et al., 2020 \\
\hline \multirow[t]{2}{*}{ Wild cabbage } & Paenibacillus sp. & \multirow[t]{2}{*}{ Xanthomonas campestris } & ISR & Ghazalibiglar et al., 2016 \\
\hline & Bacillus velezensis sp. & & Antibiosis activity & Liu et al., 2016 \\
\hline Rice & Pseudomonas sp. & Xanthomonas oryzae & $\begin{array}{l}\text { Peroxidase activity, } \\
\text { polyphenol-oxidase \& } \\
\text { phenylalanine-ammonia } \\
\text { lyase }\end{array}$ & Yasmin et al., 2016 \\
\hline Potato & $\begin{array}{l}\text { Lysinibacillus sp., Pseudomonas } \\
\text { fluorescens, Bacillus subtilis, }\end{array}$ & Ralstonia solanacearum & Antibiosis & Djaya et al., 2019 \\
\hline \multicolumn{5}{|l|}{ Fungal pathogen } \\
\hline Peanut & P. fluorescens & Sclerotium rolfsii & Antimicrobial compound & Lohitha et al., 2016 \\
\hline Cucumber & Bacillus amyloliquefaciens & Fusarium oxysporum & $\begin{array}{l}\text { Secondary metabolites, } \\
\text { ISR, Phytohormones }\end{array}$ & Liu Y. et al., 2017 \\
\hline \multirow[t]{2}{*}{ Tomato } & Paenibacillus lentimorbus & Sclerotium rolfsii & $\begin{array}{l}\text { Expression of } \\
\text { defense-related \& } \\
\text { autophagy-related genes }\end{array}$ & Dixit et al., 2018 \\
\hline & Bacillus cereus & $\begin{array}{l}\text { Alternaria solani, Fusarium } \\
\text { oxysporum }\end{array}$ & $\begin{array}{l}\text { IAA, Siderophore, Ammonia, } \\
\text { ACC deaminase, Catalase, } \\
\mathrm{N} \text {-fixation }\end{array}$ & Karthika et al., 2020 \\
\hline
\end{tabular}


TABLE 1 | Continued

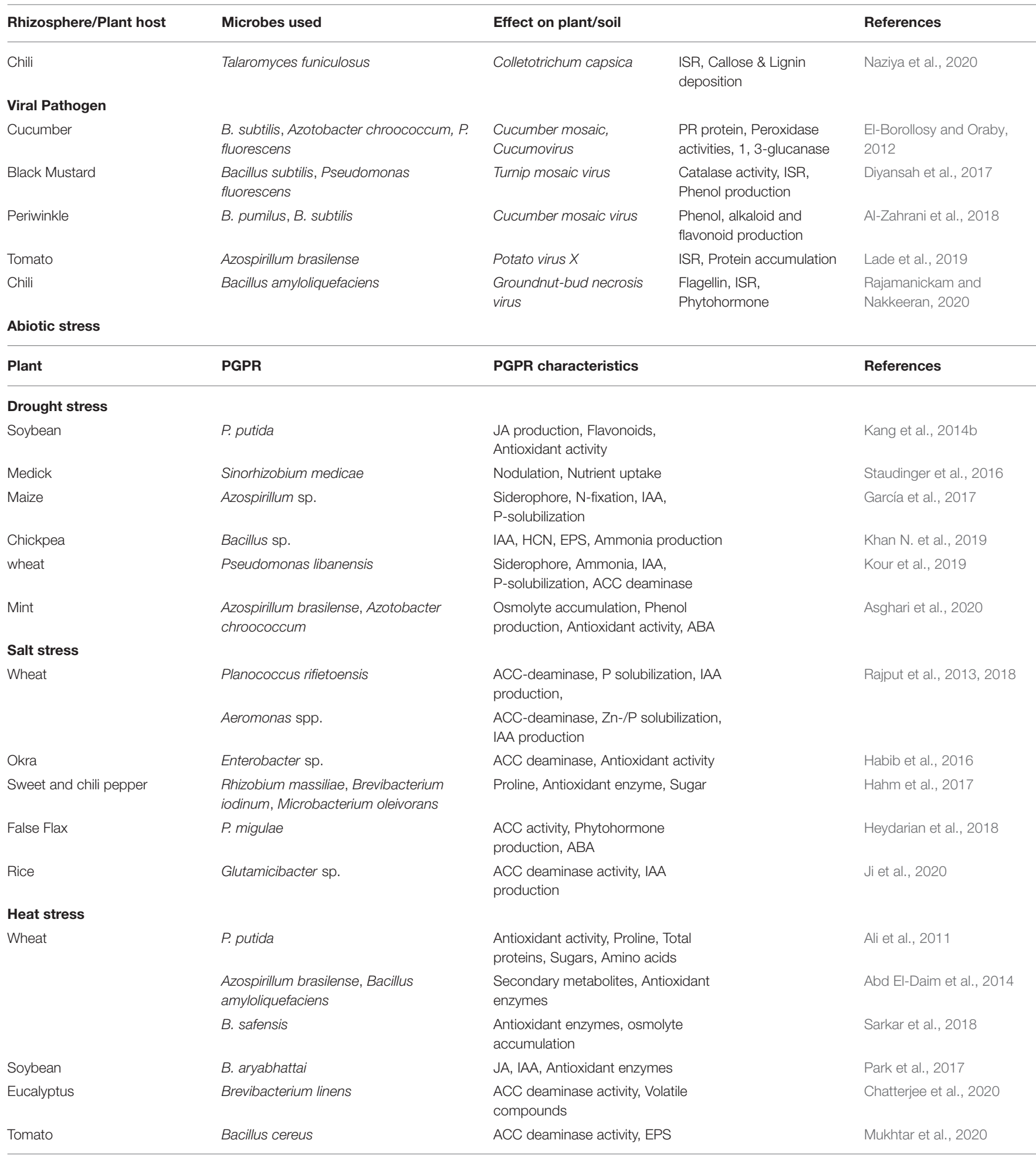

strains such as $P$. aeruginosa, Proteus penneri, and Alcaligenes faecalis produce sugar, proline, and protein content in maize plants, which helps to improve water potential, growth, and reduces water loss for inducing tolerance against drought conditions (Naseem and Bano, 2014). Drought stress decreased photosynthetic activity and chlorophyll content in soya bean plants while the application of $P$. putida mitigates water deficit conditions by improving biomass and enhancing photosynthetic machinery (Tiwari et al., 2016; Etesami, 2018). 


\section{Salinity}

Halo-tolerant rhizobacterial strains can survive in high saline soils and possess certain properties that help plants to thrive in a saline environment (Abbas et al., 2019). Different studies reported the mitigating role of PGPR against the detrimental effects of high saline conditions on various plants utilizing several mechanisms such as biofilm formation, osmolyte accumulation within the cytoplasm of the plant cell, retaining turgor pressure of salt-stressed cell, and production of EPS that binds with cations, limiting their accessibility for plant cells (Kang et al., 2014b; Egamberdieva et al., 2015; Heydarian et al., 2018; Rajput et al., 2018; Nawaz et al., 2020). PGPR also alleviate salt stressinduced secondary stresses such as osmotic and oxidative stress by producing antioxidants, phytohormones, and ISR signaling (Hahm et al., 2017; Abbas et al., 2019). The isolated B. subtilis and $B$. pumilus strains from saline soil showed various PGPR features such as phosphate solubilization, hydrogen cyanide, ammonia, and IAA production, and salt stress tolerance (Damodaran et al., 2013). In rice, co-inoculation with $P$. pseudoalcaligenes and $B$. pumilus results in increased glycine betaine levels and improve tolerance against salinity stress (Jha and Saraf, 2015). Pseudomonas sp. and Acinetobacter spp. accumulate ACC deaminase and IAA during saline stress to improve the growth of oats and barley plants (Chang et al., 2014).

PGPR induce chemical and physical changes during salinity that lead to increased growth and ISR signaling (Ji et al., 2020). Salt-tolerant strains of Azospirillum improved grain weight and growth of salt-stressed wheat plants (Nia et al., 2012). ABAmediated apoplastic acidification plays a major role in inducing salt tolerance in maize plants. Bio-priming of lettuce seeds with Azospirillum improved product quality, shelf life, and growth, during stressed conditions (Fasciglione et al., 2015). P. stutzeri, P. fluorescens, and $P$. aeruginosa strain isolated from the rhizosphere of tomato plant showed high salt levels and improves tricarboxylic acid cycle, accumulation of phytohormones and ACC deaminase resulting in enhanced salt tolerance (Tank and Saraf, 2010; De La Torre-González et al., 2018). In rice, inoculation with $B$. amyloliquefaciens enhances salinity tolerance and improves growth by producing auxin, $\mathrm{ABA}$ and regulating the expression of several salt-stressed genes (Nautiyal et al., 2013; Shahzad et al., 2017).

\section{Heat}

Global warming is a serious threat to living species, which is becoming an alarming issue worldwide. According to the report of IPCC (2007), the temperature is expected to rise by 1.8 to $3.6^{\circ} \mathrm{C}$ globally at the end of this century due to changes in climatic conditions. The increase in temperature is considered the biggest challenge in microbial colonization and crop production, resulting in protein degradation and severe cell damage. For instance, heat-shock proteins (HSPs) are specific polypeptides, which an organism can produce due to an increase in temperature. In microorganisms, different genes are implicated in the mechanism of responding to stress because PGPR possesses several mechanisms in inducing tolerance against heat stress. Numerous studies have reported that PGPR inoculation mitigated the detrimental impacts of heat stress in different plants including sorghum, wheat, chickpea, and tomato (Ali et al., 2009, 2011; Abd El-Daim et al., 2014; Issa et al., 2018). These PGPR induce tolerance by synthesizing different phytohormones, improving biofilm formations, and enhancing levels of HSPs (Ali et al., 2011; Park et al., 2017; Sarkar et al., 2018). In the chickpea plant, the application of $P$. putida showed thermotolerance by the formation of thick biofilm and expression of stress-related transcription factors.

The accumulation of proteins in heat-stressed sorghum plants is another effective mechanism of PGPR (Pseudomonas AKMP6) against abiotic stress (Ali et al., 2009). The potential of Bacillus cereus to produce several metabolites such as organic acids, IAA, GAs, essential amino acids, and HPSs enhances thermotolerance in tomato and sorghum plants (Khan et al., 2020; Mukhtar et al., 2020). However, further studies are needed to decipher the function of PGPR mediated expression of HSPs for inducing thermotolerance.

\section{PGPR-MEDIATED RHIZOSPHERE ENGINEERING FOR AGRICULTURE AND ECOSYSTEM SUSTAINABILITY}

In agriculture, it is difficult to apply sustainable and economical systems of farming, which can accommodate the new and advanced technologies (Bhat et al., 2019; Disi et al., 2019; Guo et al., 2019; Hassan et al., 2019b). The rhizosphere determines the plant's health and helps in inducing tolerance against environmental stresses by enhancing nutrient uptake, water availability, and buffering capacity. The knowledge of these plant-microbe interactions can help in developing new sustainable, eco-friendly, and economical systems for agriculture (Kumar et al., 2015; Rakshit et al., 2015; Naqqash et al., 2016). The selective aggregation of microbial populations against abiotic and biotic stresses affects plant defense and immunity in successive generations through legacy effects and soilplant feedback (Kostenko and Bezemer, 2020). The microbes responsible for disease resistance in plants could be manipulated or engineered, but it requires understanding their interaction with the environment and plant for sustainable agriculture. Table 1 summarizes different examples of PGPR involved in sustainable agriculture by stimulating growth and mitigating abiotic and biotic stresses in different crops.

The literature advocates that PGPR inoculation leads to sustainable and efficient crop production to feed a growing world population during that time when agriculture faces different environmental constraints. It is essential to fully understand the important characteristics of effective PGPR inoculants before applying them to intensive farming practices. The engineering of biopesticides and biofertilizers with improved performance for sustainable agriculture requires identification and exploration of useful genes associated with complex pathways of rhizospheric colonization, production of secondary metabolites, and specific promoters which are expressed in a particular rhizospheric environment (Hassan et al., 2019a; Hanif et al., 2020). In the future, the investigation for elucidating the role of those genes 
involved in microbe-plant interaction will help develop new tools for improving plant and soil health.

\section{CURRENT CHALLENGES AND FUTURE PERSPECTIVE}

This review has explicitly described the heterogeneous group of PGPR present in the rhizosphere with significant potential to transiently or permanently alter the rhizosphere. PGPR inoculants possess the potential for sustainable agriculture as they are one of the accepted and validated substitutes for chemical fertilizers, fungicides, and other chemical-based simulators. Over the past few decades, PGPR have started replacing chemical compounds in silviculture, horticulture, agriculture, and environmental remediation procedure. In PGPR studies, most of the research is limited to the greenhouse and laboratory level; therefore, it is necessary to take it toward the field to explore the PGPR role in the natural environment. Another critical challenge in implementing microbial inoculants includes microbes screening, their production, marketing, and commercialization. At the field and laboratory level, identification of the microbiome interactions, their diversity, impact on environmental stresses, including their mode of action is necessary.

In the future, recent and advanced technologies such as meta-proteomics, nanotechnology, and rhizoengineering must be utilized to produce eco-friendly and effective inoculants. Besides, the production of bio-formulations should focus on the type of PGPR inoculant and their ecological and physiological

\section{REFERENCES}

Abbas, R., Rasul, S., Aslam, K., Baber, M., Shahid, M., Mubeen, F., et al. (2019). Halotolerant PGPR: a hope for cultivation of saline soils. J. King Saud Univ. Sci. 31, 1195-1201. doi: 10.1016/j.jksus.2019.02.019

Abd El-Daim, I. A., Bejai, S., and Meijer, J. (2014). Improved heat stress tolerance of wheat seedlings by bacterial seed treatment. Plant Soil 379, 337-350. doi: $10.1007 /$ s11104-014-2063-3

Adesemoye, A., and Egamberdieva, D. (2013). "Beneficial effects of plant growth-promoting rhizobacteria on improved crop production: prospects for developing economies," in Bacteria in Agrobiology: Crop Productivity, eds D. Maheshwari, M. Saraf, and A. Aeron (Berlin: Springer), 45-63. doi: 10.1007/978-3-642-37241-4_2

Ahemad, M., and Kibret, M. (2014). Mechanisms and applications of plant growth promoting rhizobacteria: current perspective. J. King Saud Univ. Sci. 26, 1-20. doi: 10.1016/j.jksus.2013.05.001

Ahkami, A. H., White Iii, R. A., Handakumbura, P. P., and Jansson, C. (2017). Rhizosphere engineering: enhancing sustainable plant ecosystem productivity. Rhizosphere 3, 233-243. doi: 10.1016/j.rhisph.2017.04.012

Ahmad, M., Zahir, Z. A., Asghar, H. N., and Arshad, M. (2012). The combined application of rhizobial strains and plant growth promoting rhizobacteria improves growth and productivity of mung bean (Vigna radiata L.) under salt-stressed conditions. Ann. Microbiol. 62, 1321-1330. doi: 10.1007/s13213-011-0380-9

Akhtar, S., and Ali, B. (2011). Evaluation of rhizobacteria as non-rhizobial inoculants for mung beans. Aust. J. Crop Sci. 5:1723. Available online at: http:// www.cropj.com/ali_5_13_2011_1723_1729.pdf

Ali, S., Hameed, S., Imran, A., Iqbal, M., and Lazarovits, G. (2014). Genetic, physiological and biochemical characterization of Bacillus sp. strain RMB7 acceptance. Inoculation with ice-nucleating PGPR can be a promising technology to improve plant tolerance and growth during chilling stress. Different contaminants and nutrients can be detected by developing smart biosensors, which leads to precision farming. The involvement of nanotechnology is promising, but nano-products still needs to be of acceptable quality and cost-effective. The essential aspects of nanoparticles regarding their physical, biological, and chemical properties exhibit their potential for improving food quality, enhance plant defense, detect pathogenic infection, regulate plant growth, reduce waste and enhance food production and serve as nano-biofertilizers. The encapsulation of nano-biofertilizers can regulate the transfer of fertilizers to the specific cell and prevent unintentional loss. The main goal of farming in the future should be precision farming which is meant to reduce input and increase output by implementing targeted action and tracking environmental variables. Novel or superior PGPR strains can be developed by modifying their particular traits using genetic engineering. These manipulated PGPR can help to control plant stresses as sustainable, eco-friendly, and low-input technology.

\section{AUTHOR CONTRIBUTIONS}

$\mathrm{SH}$ and $\mathrm{TN}$ wrote the initial draft and made figures. $\mathrm{MN}$, IL, MS, and RZ helped in collection and review of literature. MM edited the manuscript. AI finalized the review. All authors contributed to the article and approved the submitted version. exhibiting plant growth promoting and broad spectrum antifungal activities. Microb. Cell Fact. 13:144. doi: 10.1186/PREACCEPT-6657919731258908

Ali, S., Hameed, S., Shahid, M., Iqbal, M., Lazarovits, G., and Imran, A. (2020). Functional characterization of potential PGPR exhibiting broad-spectrum antifungal activity. Microbiol. Res. 232:126389. doi: 10.1016/j.micres.2019.126389

Ali, S. Z., Sandhya, V., Grover, M., Kishore, N., Rao, L. V., and Venkateswarlu, B. (2009). Pseudomonas sp. strain AKM-P6 enhances tolerance of sorghum seedlings to elevated temperatures. Biol. Fertil. Soils 46, 45-55. doi: 10.1007/s00374-009-0404-9

Ali, S. Z., Sandhya, V., Grover, M., Linga, V. R., and Bandi, V. (2011). Effect of inoculation with a thermotolerant plant growth promoting Pseudomonas putida strain AKMP7 on growth of wheat (Triticum spp.) under heat stress. J. Plant Interact. 6, 239-246. doi: 10.1080/17429145.2010.545147

Alori, E. T., Glick, B. R., and Babalola, O. O. (2017). Microbial phosphorus solubilization and its potential for use in sustainable agriculture. Front. Microbiol. 8:971. doi: 10.3389/fmicb.2017.00971

Al-Zahrani, H. S. M., Elbeshehy, E. K. F., Aldhebiani, A. Y., and Elbeaino, T. (2018). Effect of Cucumber mosaic virus (CMV) infection on antineoplastic alkaloids from periwinkle (Catharanthus roseus L.) cultured in the Mecca region and resistance induction by plant-growthpromoting rhizobacteria (PGPR). Biotechnol. Biotechnol. Equip. 32, 49-57. doi: 10.1080/13102818.2017.1395298

Andrews, M., and Andrews, M. E. (2017). Specificity in legumerhizobia symbioses. Int. J. Mol. Sci. 18:705. doi: 10.3390/ijms180 40705

Arif, M. S., Muhammad, R., Shahzad, S. M., Yasmeen, T., Shafaqat, A., and Akhtar, M. J. (2017). Phosphorus-mobilizing rhizobacterial strain Bacillus cereus GS6 improves symbiotic efficiency of soybean on an Aridisol 
amended with phosphorus-enriched compost. Pedosphere 27, 1049-1061. doi: 10.1016/S1002-0160(17)60366-7

Asari, S., Tarkowská, D., Rolčík, J., Novák, O., Palmero, D. V., Bejai, S., et al. (2017). Analysis of plant growth-promoting properties of Bacillus amyloliquefaciens UCMB5113 using Arabidopsis thaliana as host plant. Planta 245, 15-30. doi: 10.1007/s00425-016-2580-9

Asghari, B., Khademian, R., and Sedaghati, B. (2020). Plant growth promoting rhizobacteria (PGPR) confer drought resistance and stimulate biosynthesis of secondary metabolites in pennyroyal (Mentha pulegium L.) under water shortage condition. Sci. Hortic. 263:109132. doi: 10.1016/j.scienta.2019.109132

Atzorn, R., Crozier, A., Wheeler, C., and Sandberg, G. (1988). Production of gibberellins and indole-3-acetic acid by Rhizobium phaseoli in relation to nodulation of Phaseolus vulgaris roots. Planta 175, 532-538. doi: 10.1007/BF00393076

Aw, X., Li, Z., Wc, L., and Zh, Y. (2019). The effect of plant growthpromoting rhizobacteria (PGPR) on arsenic accumulation and the growth of rice plants (Oryza sativa L.). Chemosphere 242:125136. doi: 10.1016/j.chemosphere.2019.125136

Awan, H. A., Imran, A., Zaheer, A., Mirza, S., and Malik, K. A. (2011). "Microbial diversity and molecular signals controlling plant-microbe interaction in the rhizosphere of grasses including wheat," in Proceedings of the Plant GrowthPromoting Rhizobacteria for Sustainable Agriculture, eds M. Reddy, Q. Wang, (Beijing: Asian PGPR), 210. Available online at: http://asianpgpr.com/secondasian-pgpr-conference.php

Azeem, M., Riaz, A., Chaudhary, A. N., Hayat, R., Hussain, Q., Tahir, M. I., et al. (2015). Microbial phytase activity and their role in organic P mineralization. Arch. Agron. Soil Sci. 61, 751-766. doi: 10.1080/03650340.2014.963796

Bano, S. A., and Iqbal, S. M. (2016). Biological nitrogen fixation to improve plant growth and productivity. Int. J. Agric. Innov. Res. 4, 596-599. Available online at: https://ijair.org/index.php/issues?view=publication\&task=show\&id=665

Beeckman, F., Motte, H., and Beeckman, T. (2018). Nitrification in agricultural soils: impact, actors and mitigation. Curr. Opin. Biotechnol. 50, 166-173. doi: 10.1016/j.copbio.2018.01.014

Behera, B., Yadav, H., Singh, S., Mishra, R., Sethi, B., Dutta, S., et al. (2017). Phosphate solubilization and acid phosphatase activity of Serratia sp. isolated from mangrove soil of Mahanadi river delta, Odisha, India. J. Genet. Eng. Biotechnol. 15, 169-178. doi: 10.1016/j.jgeb.2017.01.003

Berendsen, R. L., Vismans, G., Yu, K., Song, Y., De Jonge, R., Burgman, W. P., et al. (2018). Disease-induced assemblage of a plant-beneficial bacterial consortium. ISME J. 12, 1496-1507. doi: 10.1038/s41396-018-0093-1

Bhat, M., Rasool, R., and Ramzan, S. (2019). Plant growth promoting rhizobacteria (PGPR) for sustainable and eco-friendly agriculture. Acta Sci. Agric. 3, 23-25. Available online at: https://www.actascientific.com/ASAG/pdf/ASAG-03-0287. pdf

Bhattacharyya, P. N., and Jha, D. K. (2012). Plant growth-promoting rhizobacteria (PGPR): emergence in agriculture. World J. Microb. Biot. 28, 1327-1350. doi: 10.1007/s11274-011-0979-9

Bianco, C., and Defez, R. (2010). Improvement of phosphate solubilization and Medicago plant yield by an indole-3-acetic acid-overproducing strain of Sinorhizobium meliloti. Appl. Environ. Microbiol. 76, 4626-4632. doi: 10.1128/AEM.02756-09

Bibi, N., Hamayun, M., Khan, S. A., Iqbal, A., Islam, B., Shah, F., et al. (2018). Anthracene biodegradation capacity of newly isolated rhizospheric bacteria Bacillus cereus S13. PLoS ONE 13:e0201620. doi: 10.1371/journal.pone.0201620

Binenbaum, J., Weinstain, R., and Shani, E. (2018). Gibberellin localization and transport in plants. Trends Plant Sci. 23, 410-421. doi: $10.1016 /$ j.tplants.2018.02.005

Bjarnsholt, T., Van Gennip, M., Jakobsen, T. H., Christensen, L. D., Jensen, P. Ø., and Givskov, M. (2010). In vitro screens for quorum sensing inhibitors and in vivo confirmation of their effect. Nat. Protoc. 5:282. doi: 10.1038/nprot.2009.205

Budi, S., Van Tuinen, D., Arnould, C., Dumas-Gaudot, E., GianinazziPearson, V., and Gianinazzi, S. (2000). Hydrolytic enzyme activity of Paenibacillus sp. strain B2 and effects of the antagonistic bacterium on cell integrity of two soil-borne pathogenic fungi. Appl. Soil Ecol. 15, 191-199. doi: 10.1016/S0929-1393(00)00095-0

Bukhat, S., Imran, A., Javaid, S., Shahid, M., Majeed, A., and Naqqash, T. (2020). Communication of plants with microbial world: exploring the regulatory networks for PGPR mediated defense signaling. Microbiol. Res. 238:126486. doi: $10.1016 /$ j.micres.2020.126486
Cabeza, R. A., Steingrobe, B., and Claassen, N. (2019). Phosphorus fractionation in soils fertilized with recycled phosphorus products. J. Soil Sci. Plant Nutr. 19, 611-619. doi: 10.1007/s42729-019-00061-8

Calvo, P., Zebelo, S., Mcnear, D., Kloepper, J., and Fadamiro, H. (2019). Plant growth-promoting rhizobacteria induce changes in Arabidopsis thaliana gene expression of nitrate and ammonium uptake genes. J. Plant Interact. 14, 224-231. doi: 10.1080/17429145.2019.1602887

Cha, J.-Y., Han, S., Hong, H.-J., Cho, H., Kim, D., Kwon, Y., et al. (2016). Microbial and biochemical basis of a Fusarium wilt-suppressive soil. ISME J. 10, 119-129. doi: 10.1038 /ismej.2015.95

Chane, A., Barbey, C., Bourigault, Y., Maillot, O., Rodrigues, S., Bouteiller, M., et al. (2019). A flavor lactone mimicking AHL quorum-sensing signals exploits the broad affinity of the QsdR regulator to stimulate transcription of the rhodococcal qsd operon involved in quorum-quenching and biocontrol activities. Front. Microbiol. 10:786. doi: 10.3389/fmicb.2019.00786

Chang, P., Gerhardt, K. E., Huang, X.-D., Yu, X.-M., Glick, B. R., Gerwing, P. D., et al. (2014). Plant growth-promoting bacteria facilitate the growth of barley and oats in salt-impacted soil: implications for phytoremediation of saline soils. Int. J. Phytoremediation 16, 1133-1147. doi: 10.1080/15226514.2013.821447

Chatterjee, P., Kanagendran, A., Samaddar, S., Pazouki, L., Sa, T.-M., and Niinemets, $\ddot{U}$. (2020). Influence of Brevibacterium linens RS16 on foliage photosynthetic and volatile emission characteristics upon heat stress in Eucalyptus grandis. Sci. Total Environ. 700:134453. doi: 10.1016/j.scitotenv.2019.134453

Chen, M., Wang, J., Liu, B., Zhu, Y., Xiao, R., Yang, W., et al. (2020). Biocontrol of tomato bacterial wilt by the new strain Bacillus velezensis FJAT-46737 and its lipopeptides. BMC Microbiol. 20:160. doi: 10.1186/s12866-020-01851-2

Chialva, M., Salvioli Di Fossalunga, A., Daghino, S., Ghignone, S., Bagnaresi, P., Chiapello, M., et al. (2018). Native soils with their microbiotas elicit a state of alert in tomato plants. New Phytol. 220, 1296-1308. doi: 10.1111/nph.15014

Clemens, S. (2014). $\mathrm{Zn}$ and Fe biofortification: the right chemical environment for human bioavailability. Plant Sci. 225, 52-57. doi: 10.1016/j.plantsci.2014.05.014

Cohen, A. C., Bottini, R., Pontin, M., Berli, F. J., Moreno, D., Boccanlandro, H., et al. (2015). Azospirillum brasilense ameliorates the response of Arabidopsis thaliana to drought mainly via enhancement of ABA levels. Physiol. Plant. 153, 79-90. doi: 10.1111/ppl.12221

Collavino, M. M., Tripp, H. J., Frank, I. E., Vidoz, M. L., Calderoli, P. A., Donato, M., et al. (2014). nifH pyrosequencing reveals the potential for location-specific soil chemistry to influence $\mathrm{N}_{2}$-fixing community dynamics. Environ. Microbiol. 16, 3211-3223. doi: 10.1111/1462-2920.12423

Dai, L., Zhang, G., Yu, Z., Ding, H., Xu, Y., and Zhang, Z. (2019). Effect of drought stress and developmental stages on microbial community structure and diversity in peanut rhizosphere soil. Int. J. Mol. Sci. 20:2265. doi: $10.3390 /$ ijms 20092265

Damodaran, T., Sah, V., Rai, R., Sharma, D., Mishra, V., Jha, S., et al. (2013). Isolation of salt tolerant endophytic and rhizospheric bacteria by natural selection and screening for promising plant growth-promoting rhizobacteria (PGPR) and growth vigour in tomato under sodic environment. Afr. J. Microbiol. Res. 7, 5082-5089. doi: 10.5897/AJMR2013.6003

De La Torre-González, A., Montesinos-Pereira, D., Blasco, B., and Ruiz, J. (2018). Influence of the proline metabolism and glycine betaine on tolerance to salt stress in tomato (Solanum lycopersicum L.) commercial genotypes. J. Plant Physiol. 231, 329-336. doi: 10.1016/j.jplph.2018.10.013

De Meyer, S. E., De Beuf, K., Vekeman, B., and Willems, A. (2015). A large diversity of non-rhizobial endophytes found in legume root nodules in Flanders (Belgium). Soil Biol. Biochem. 83, 1-11. doi: 10.1016/j.soilbio.2015. 01.002

Defoirdt, T. (2018). Quorum-sensing systems as targets for antivirulence therapy. Trends Microbiol. 26, 313-328. doi: 10.1016/j.tim.2017.10.005

Dessaux, Y., Grandclément, C., and Faure, D. (2016). Engineering the rhizosphere. Trends Plant Sci. 21, 266-278. doi: 10.1016/j.tplants.2016.01.002

Disi, J. O., Mohammad, H. K., Lawrence, K., Kloepper, J., and Fadamiro, H. (2019). A soil bacterium can shape belowground interactions between maize, herbivores and entomopathogenic nematodes. Plant Soil 437, 83-92. doi: 10.1007/s11104-019-03957-7

Dixit, R., Agrawal, L., Singh, S. P., Singh, P. C., Prasad, V., and Chauhan, P. S. (2018). Paenibacillus lentimorbus induces autophagy for protecting tomato from Sclerotium rolfsii infection. Microbiol. Res. 215, 164-174. doi: $10.1016 /$ j.micres.2018.07.008 
Diyansah, B., Aini, L. Q., and Hadiastono, T. (2017). The effect of PGPR (plant growth promoting rhizobacteria) Pseudomonas fluorescens and Bacillus subtilis on leaf mustard plant (Brassica juncea L.) infected by TuMV (Turnip mosaic virus). Int. J. Plant Prot. 1, 30-38. Available online at: https://jtpp.ub.ac.id/ index.php/jtpp/article/view/102

Djaya, L., Istifadah, N., Hartati, S., and Joni, I. M. (2019). In vitro study of plant growth promoting rhizobacteria (PGPR) and endophytic bacteria antagonistic to Ralstonia solanacearum formulated with graphite and silica nano particles as a biocontrol delivery system (BDS). Biocatal. Agric. Biotechnol. 19:101153. doi: 10.1016/j.bcab.2019.101153

Egamberdieva, D., Jabborova, D., and Hashem, A. (2015). Pseudomonas induces salinity tolerance in cotton (Gossypium hirsutum) and resistance to Fusarium root rot through the modulation of indole-3-acetic acid. Saudi J. Biol. Sci. 22, 773-779. doi: 10.1016/j.sjbs.2015.04.019

Ejaz, S., Batool, S., Anjum, M. A., Naz, S., Qayyum, M. F., Naqqash, T., et al. (2020). Effects of inoculation of root-associative Azospirillum and Agrobacterium strains on growth, yield and quality of pea (Pisum sativum L.) grown under different nitrogen and phosphorus regimes. Sci. Hortic. 270:109401. doi: $10.1016 /$ j.scienta.2020.109401

El-Borollosy, A. M., and Oraby, M. M. (2012). Induced systemic resistance against Cucumber mosaic cucumovirus and promotion of cucumber growth by some plant growth-promoting rhizobacteria. Ann. Agric. Sci. 57, 91-97. doi: $10.1016 /$ j.aoas.2012.08.001

Etesami, H. (2018). Can interaction between silicon and plant growth promoting rhizobacteria benefit in alleviating abiotic and biotic stresses in crop plants? Agric. Ecosyst. Environ. 253, 98-112. doi: 10.1016/j.agee.2017.11.007

Fageria, N. (2014). Yield and yield components and phosphorus use efficiency of lowland rice genotypes. J. Plant Nutr. 37, 979-989. doi: 10.1080/01904167.2014.888735

Fahimi, A., Ashouri, A., Ahmadzadeh, M., Hoseini Naveh, V., Asgharzadeh, A., Maleki, F., et al. (2014). Effect of PGPR on population growth parameters of cotton aphid. Arch. Phytopathol. Plant Protect. 47, 1274-1285. doi: 10.1080/03235408.2013.840099

FAO (2019). World Fertilizer Trends and Outlook to 2022. Rome.

Fasciglione, G., Casanovas, E. M., Quillehauquy, V., Yommi, A. K., Goñi, M. G., Roura, S. I., et al. (2015). Azospirillum inoculation effects on growth, product quality and storage life of lettuce plants grown under salt stress. Sci. Hortic. 195, 154-162. doi: 10.1016/j.scienta.2015.09.015

Fetzner, S. (2015). Quorum quenching enzymes. J. Biotechnol. 201, 2-14. doi: 10.1016/j.jbiotec.2014.09.001

Gaby, J. C., Rishishwar, L., Valderrama-Aguirre, L. C., Green, S. J., Valderrama-Aguirre, A., Jordan, I. K., et al. (2018). Diazotroph community characterization via a high-throughput nifH amplicon sequencing and analysis pipeline. Appl. Environ. Microbiol. 84:e01512-17. doi: 10.1128/AEM. 01512-17

Gamalero, E., and Glick, B. R. (2015). Bacterial modulation of plant ethylene levels. Plant Physiol. 169, 13-22. doi: 10.1104/pp.15.00284

García, J. E., Maroniche, G., Creus, C., Suárez-Rodríguez, R., RamirezTrujillo, J. A., and Groppa, M. D. (2017). In vitro PGPR properties and osmotic tolerance of different Azospirillum native strains and their effects on growth of maize under drought stress. Microbiol. Res. 202, 21-29. doi: 10.1016/j.micres.2017.04.007

García-Contreras, R., Maeda, T., and Wood, T. K. (2016). Can resistance against quorum-sensing interference be selected? ISME J. 10, 4-10. doi: $10.1038 /$ ismej.2015.84

Ghazalibiglar, H., Hampton, J. G., De Jong, E. V. Z., and Holyoake, A. (2016). Is induced systemic resistance the mechanism for control of black rot in Brassica oleracea by a Paenibacillus sp.? Biol. Control 92, 195-201. doi: 10.1016/j.biocontrol.2015.10.014

Ghosh, S. K., Bera, T., and Chakrabarty, A. M. (2020). Microbial siderophore-A boon to agricultural sciences. Biol. Control 144, 104214. doi: 10.1016/j.biocontrol.2020.104214

Glick, B. R. (2012). Plant growth-promoting bacteria: mechanisms and applications. Scientifica 2012:963401. doi: 10.6064/2012/963401

Gopalakrishnan, S., Srinivas, V., Alekhya, G., Prakash, B., Kudapa, H., Rathore, A., et al. (2015). The extent of grain yield and plant growth enhancement by plant growth-promoting broad-spectrum Streptomyces sp. in chickpea. Springer Plus 4:31. doi: 10.1186/s40064-015-0811-3
Goteti, P. K., Emmanuel, L. D. A., Desai, S., and Shaik, M. H. A. (2013). Prospective zinc solubilising bacteria for enhanced nutrient uptake and growth promotion in maize (Zea mays L.). Int. J. Microbiol. 2013:869697. doi: $10.1155 / 2013 / 869697$

Grandclément, C., Tannières, M., Moréra, S., Dessaux, Y., and Faure, D. (2016). Quorum quenching: role in nature and applied developments. FEMS Microbiol. Rev. 40, 86-116. doi: 10.1093/femsre/fuv038

Großkinsky, D. K., Tafner, R., Moreno, M. V., Stenglein, S. A., De Salamone, I. E. G., Nelson, L. M., et al. (2016). Cytokinin production by Pseudomonas fluorescens G20-18 determines biocontrol activity against Pseudomonas syringae in Arabidopsis. Sci. Rep. 6:23310. doi: 10.1038/srep23310

Gull, M., and Hafeez, F. Y. (2012). Characterization of siderophore producing bacterial strain Pseudomonas fluorescens Mst 8.2 as plant growth promoting and biocontrol agent in wheat. Afr. J. Microbiol. Res. 6, 6308-6318. doi: 10.5897/AJMR12.1285

Gunarathne, V., Mayakaduwa, S., Ashiq, A., Weerakoon, S. R., Biswas, J. K., and Vithanage, M. (2019). "Transgenic plants: benefits, applications, and potential risks in phytoremediation," in Transgenic Plant Technology for Remediation of Toxic Metals and Metalloids, ed M. N. V. Prasad (Hyderabad: Elsevier), 89-102. doi: 10.1016/B978-0-12-814389-6.00005-5

Guo, Q., Li, Y., Lou, Y., Shi, M., Jiang, Y., Zhou, J., et al. (2019). Bacillus amyloliquefaciens Ba13 induces plant systemic resistance and improves rhizosphere microecology against tomato yellow leaf curl virus disease. Appl. Soil Ecol. 137, 154-166. doi: 10.1016/j.apsoil.2019.01.015

Gupta, G., Parihar, S. S., Ahirwar, N. K., Snehi, S. K., and Singh, V. (2015). Plant growth promoting rhizobacteria (PGPR): current and future prospects for development of sustainable agriculture. J. Microb. Biochem. Technol. 7, 096-102. doi: 10.4172/1948-5948.1000188

Habib, S. H., Kausar, H., and Saud, H. M. (2016). Plant growth-promoting rhizobacteria enhance salinity stress tolerance in okra through ROS-scavenging enzymes. Biomed Res. Int. 2016:6284547. doi: 10.1155/2016/6284547

Hafeez, B., Khanif, Y., and Saleem, M. (2013). Role of zinc in plant nutrition-a review. J. Exp. Agric. Int. 3, 374-391. doi: 10.9734/AJEA/2013/2746

Hahm, M.-S., Son, J.-S., Hwang, Y.-J., Kwon, D.-K., and Ghim, S.-Y. (2017). Alleviation of salt stress in pepper (Capsicum annum L.) plants by plant growth-promoting rhizobacteria. J. Microbiol. Biotechnol. 27, 1790-1797. doi: $10.4014 / \mathrm{jmb} .1609 .09042$

Hakim, S., Imran, A., and Mirza, M. S. (2020a). Phylogenetic diversity analysis reveals Bradyrhizobium yuanmingense and Ensifer aridi as major symbionts of mung bean (Vigna radiata L.) in Pakistan. Braz. J. Microbiol. 1-14. doi: 10.1007/s42770-020-00397-9

Hakim, S., Mirza, B. S., Imran, A., Zaheer, A., Yasmin, S., Mubeen, F., et al. (2020b). Illumina sequencing of 16S rRNA tag shows disparity in rhizobial and non-rhizobial diversity associated with root nodules of mung bean (Vigna radiata L.) growing in different habitats in Pakistan. Microbiol. Res. 231:126356. doi: 10.1016/j.micres.2019.126356

Hakim, S., Mirza, B. S., Zaheer, A., Mclean, J. E., Imran, A., Yasmin, S., et al. (2018). Retrieved 16S rRNA and nifH sequences reveal co-dominance of Bradyrhizobium and Ensifer (Sinorhizobium) strains in field-collected root nodules of the promiscuous host Vigna radiata (L.) R. Wilczek. Appl. Microbiol. Biotechnol. 102, 485-497. doi: 10.1007/s00253-017-8609-6

Hanif, M. K., Malik, K. A., Hameed, S., Saddique, M. J., Fatima, K., Naqqash, T., et al. (2020). Growth stimulatory effect of AHL producing Serratia spp. from potato on homologous and non-homologous host plants. Microbiol. Res. 238:126506. doi: 10.1016/j.micres.2020.126506

Hassan, M. K., Mcinroy, J. A., Jones, J., Shantharaj, D., Liles, M. R., and Kloepper, J. W. (2019a). Pectin-rich amendment enhances soybean growth promotion and nodulation mediated by Bacillus velezensis strains. Plants 8:120. doi: 10.3390/plants 8050120

Hassan, M. K., Mcinroy, J. A., and Kloepper, J. W. (2019b). The interactions of rhizodeposits with plant growth-promoting rhizobacteria in the rhizosphere: a review. Agriculture 9:142. doi: 10.3390/agriculture9070142

Heydarian, Z., Gruber, M., Glick, B. R., and Hegedus, D. D. (2018). Gene expression patterns in roots of Camelina sativa with enhanced salinity tolerance arising from inoculation of soil with plant growth promoting bacteria producing 1-aminocyclopropane-1-carboxylate deaminase or expression the corresponding acds gene. Front. Microbiol. 9:1297. doi: $10.3389 /$ fmicb.2018.01297 
Hider, R. C., and Kong, X. (2010). Chemistry and biology of siderophores. Nat. Prod. Rep. 27, 637-657. doi: 10.1039/b906679a

Htwe, A. Z., Moh, S. M., Moe, K., and Yamakawa, T. (2018). Effects of co-inoculation of Bradyrhizobium japonicum SAY3-7 and Streptomyces griseoflavus P4 on plant growth, nodulation, nitrogen fixation, nutrient uptake, and yield of soybean in a field condition. Soil Sci. Plant Nutr. 64, 222-229. doi: 10.1080/00380768.2017.14 21436

Htwe, A. Z., Moh, S. M., Soe, K. M., Moe, K., and Yamakawa, T. (2019). Effects of biofertilizer produced from Bradyrhizobium and Streptomyces griseoflavus on plant growth, nodulation, nitrogen fixation, nutrient uptake, and seed yield of mung bean, cowpea, and soybean. Agronomy 9:77. doi: 10.3390/agronomy9020077

Hu, L., Robert, C. A., Cadot, S., Zhang, X., Ye, M., Li, B., et al. (2018). Root exudate metabolites drive plant-soil feedbacks on growth and defense by shaping the rhizosphere microbiota. Nat. Commun. 9, 1-13. doi: 10.1038/s41467-018-05122-7

Imran, A., Hafeez, F. Y., Fruhling, A., Schumann, P., Malik, K. A., and Stackebrandt, E. (2010). Ochrobactrum ciceri sp. nov., isolated from nodules of Cicer arietinum. Int. J. Syst. Evol. Microbiol. 60, 1548-1553. doi: 10.1099/ijs.0.013987-0

Imran, A., Mirza, M. S., Shah, T. M., Malik, K. A., and Hafeez, F. Y. (2015). Differential response of kabuli and desi chickpea genotypes toward inoculation with PGPR in different soils. Front. Microbiol. 6:859. doi: $10.3389 /$ fmicb.2015.00859

Imran, A., Saadalla, M. J. A., Khan, S.-U., Mirza, M. S., Malik, K. A., and Hafeez, F. Y. (2014). Ochrobactrum sp. Pv2Z2 exhibits multiple traits of plant growth promotion, biodegradation and $\mathrm{N}$-acyl-homoserine-lactone quorum sensing. Ann. Microbiol. 64, 1797-1806. doi: 10.1007/s13213-014-0824-0

IPCC (2007). "Mitigation of climate change", in Climate Change 2007: Mitigation. Contribution of Working Group III to the Fourth Assessment Report of the Intergovernmental Panel on Climate Change, ed B. Metz (New York, NY: Cambridge University Press), 1-850. Available online at: https://www.ipcc.ch/ site/assets/uploads/2018/03/ar4_wg3_full_report-1.pdf

Ipek, M., Aras, S., Arikan, S., Eşitken, A., Pirlak, L., Dönmez, M. F., et al. (2017). Root plant growth promoting rhizobacteria inoculations increase ferric chelate reductase (FC-R) activity and Fe nutrition in pear under calcareous soil conditions. Sci. Hortic. 219, 144-151. doi: 10.1016/j.scienta.2017.02.043

Iqbal Hussain, M., Naeem Asghar, H., Javed Akhtar, M., and Arshad, M. (2013). Impact of phosphate solubilizing bacteria on growth and yield of maize. Soil Environ. 32, 71-78. Available online at: http://www.se.org.pk/Papers.aspx? issueid $=67$

Iqbal, U., Jamil, N., Ali, I., and Hasnain, S. (2010). Effect of zinc-phosphatesolubilizing bacterial isolates on growth of Vigna radiata. Ann. Microbiol. 60, 243-248. doi: 10.1007/s13213-010-0033-4

Islam, S., Akanda, A. M., Prova, A., Islam, M. T., and Hossain, M. M. (2016). Isolation and identification of plant growth promoting rhizobacteria from cucumber rhizosphere and their effect on plant growth promotion and disease suppression. Front. Microbiol. 6:1360. doi: 10.3389/fmicb.2015.01360

Issa, A., Esmaeel, Q., Sanchez, L., Courteaux, B., Guise, J.-F., Gibon, Y., et al. (2018). Impacts of Paraburkholderia phytofirmans strain PsJN on tomato (Lycopersicon esculentum L.) under high temperature. Front. Plant Sci. 9:1397. doi: $10.3389 /$ fpls.2018.01397

Jakkula, V., and Wani, S. (2018). Zeolites: potential soil amendments for improving nutrient and water use efficiency and agriculture productivity. Sci. Rev. Chem.l Commun. 8, 1-15. Available online at: http://oar.icrisat.org/id/eprint/10768

Jha, C. K., and Saraf, M. (2015). Plant growth promoting rhizobacteria (PGPR): a review. J. Agric. Res. Dev. 5, 108-119. doi: 10.3389/fpls.2018.01473

Ji, J., Yuan, D., Jin, C., Wang, G., Li, X., and Guan, C. (2020). Enhancement of growth and salt tolerance of rice seedlings (Oryza sativa L.) by regulating ethylene production with a novel halotolerant PGPR strain Glutamicibacter sp. YD01 containing ACC deaminase activity. Acta Physiol. Plant. 42, 1-17. doi: 10.1007/s11738-020-3034-3

Jiang, S., Zhang, D., Wang, L., Pan, J., Liu, Y., Kong, X., et al. (2013). A maize calcium-dependent protein kinase gene, $\mathrm{ZmCPK} 4$, positively regulated abscisic acid signaling and enhanced drought stress tolerance in transgenic Arabidopsis. Plant Physiol. Biochem. 71, 112-120. doi: 10.1016/j.plaphy.2013.07.004
Jing, H., Xia, X., Liu, H., Zhou, Z., Wu, C., and Nagarajan, S. (2015). Anthropogenic impact on diazotrophic diversity in the mangrove rhizosphere revealed by nifH pyrosequencing. Front. Microbiol. 6:1172. doi: 10.3389/fmicb.2015.01172

Joshi, M., Srivastava, R., Sharma, A. K., and Prakash, A. (2015). Screening of resistant varieties and antagonistic Fusarium oxysporum for biocontrol of Fusarium wilt of chilli. J. Plant Pathol. Microbiol. 3:5. doi: 10.4172/2157-7471.1000134

Kalayu, G. (2019). Phosphate solubilizing microorganisms: promising approach as biofertilizers. Int. J. Agron. 2019:4917256. doi: 10.1155/2019/4917256

Kamran, S., Shahid, I., Baig, D. N., Rizwan, M., Malik, K. A., and Mehnaz, S. (2017). Contribution of zinc solubilizing bacteria in growth promotion and zinc content of wheat. Front. Microbiol. 8:2593. doi: 10.3389/fmicb.2017.02593

Kang, M., Hamayun, M., Waqas, M., Kim, J., Shinwari, Z. K., and Lee, I. (2016). Burkholderia SP. KCTC 11096BP modulates pepper growth and resistance against Phytophthora capsici. Pak. J. Bot. 48, 1965-1970. Available online at: https://www.pakbs.org/pjbot/PDFs/48(5)/23.pdf

Kang, S.-M., Hamayun, M., Khan, M. A., Iqbal, A., and Lee, I.-J. (2019a). Bacillus subtilis JW1 enhances plant growth and nutrient uptake of Chinese cabbage through gibberellins secretion. J. Appl. Bot. Food Qual. 92, 172-178. doi: 10.5073/JABFQ.2019.092.023

Kang, S.-M., Khan, A. L., Hamayun, M., Hussain, J., Joo, G.-J., You, Y.H., et al. (2012). Gibberellin-producing Promicromonospora sp. SE188 improves Solanum lycopersicum plant growth and influences endogenous plant hormones. J. Microbiol. 50, 902-909. doi: 10.1007/s12275-012-2273-4

Kang, S.-M., Khan, A. L., Waqas, M., Asaf, S., Lee, K.-E., Park, Y.-G., et al. (2019b). Integrated phytohormone production by the plant growth-promoting rhizobacterium Bacillus tequilensis SSB07 induced thermotolerance in soybean. J. Plant Int. 14, 416-423. doi: 10.1080/17429145.2019.1640294

Kang, S.-M., Khan, A. L., Waqas, M., You, Y.-H., Hamayun, M., Joo, G.-J., et al. (2015). Gibberellin-producing Serratia nematodiphila PEJ1011 ameliorates low temperature stress in Capsicum annuum L. Eur. J. Soil Biol. 68, 85-93. doi: 10.1016/j.ejsobi.2015.02.005

Kang, S.-M., Khan, A. L., You, Y.-H., Kim, J.-G., Kamran, M., and Lee, I.-J. (2014a). Gibberellin production by newly isolated strain Leifsonia soli SE134 and its potential to promote plant growth. J. Microbiol. Biotechnol. 24, 106-112. doi: $10.4014 / \mathrm{jmb} .1304 .04015$

Kang, S.-M., Radhakrishnan, R., Khan, A. L., Kim, M.-J., Park, J.-M., Kim, B.-R., et al. (2014b). Gibberellin secreting rhizobacterium, Pseudomonas putida $\mathrm{H}-$ 2-3 modulates the hormonal and stress physiology of soybean to improve the plant growth under saline and drought conditions. Plant Physiol. Biochem. 84, 115-124. doi: 10.1016/j.plaphy.2014.09.001

Kang, S.-M., Waqas, M., Hamayun, M., Asaf, S., Khan, A. L., Kim, A.-Y., et al. (2017). Gibberellins and indole-3-acetic acid producing rhizospheric bacterium Leifsonia xyli SE134 mitigates the adverse effects of copper-mediated stress on tomato. J. Plant Int. 12, 373-380. doi: 10.1080/17429145.2017.1370142

Karnwal, A. (2017). Isolation and identification of plant growth promoting rhizobacteria from maize (Zea mays L.) rhizosphere and their plant growth promoting effect on rice (Oryza sativa L.). J. Plant Protect. Res. 57, 144-151. doi: 10.1515/jppr-2017-0020

Karthika, S., Midhun, S. J., and Jisha, M. (2020). A potential antifungal and growthpromoting bacterium Bacillus sp. KTMA4 from tomato rhizosphere. Microb. Pathog. 142:104049. doi: 10.1016/j.micpath.2020.104049

Kaviyarasi, K., Kanimozhi, K., Madhanraj, P., Panneerselvam, A., and Ambikapathy, V. (2011). Isolation, identification and molecular characterization of phosphate solubilizing actinomycetes isolated from the coastal region of Manora, Thanjavur (Dt.). Asian J. Pharm. Sci. 1, 119-122. Available online at: https://ajptonline.com/AbstractView.aspx? $\mathrm{PID}=2011-1-4-5$

Kechid, M., Desbrosses, G., Rokhsi, W., Varoquaux, F., Djekoun, A., and Touraine, B. (2013). The NRT 2.5 and NRT 2.6 genes are involved in growth promotion of Arabidopsis by the plant growth-promoting rhizobacterium (PGPR) strain Phyllobacterium brassicacearum STM 196. New Phytol. 198, 514-524. doi: 10.1111/nph.12158

Kesten, C., Gámez-Arjona, F. M., Menna, A., Scholl, S., Dora, S., Huerta, A. I., et al. (2019). Pathogen-induced $\mathrm{pH}$ changes regulate the growthdefense balance in plants. EMBO J. 38:e101822. doi: 10.15252/embj.20191 01822 
Khalid, S., Asghar, H. N., Akhtar, M. J., Aslam, A., and Zahir, Z. A. (2015). Biofortification of iron in chickpea by plant growth promoting rhizobacteria. Pak. J. Bot. 47, 1191-1194. Available online at: https://www.pakbs.org/pjbot/ PDFs/47(3)/48.pdf

Khan, M. A., Asaf, S., Khan, A. L., Jan, R., Kang, S.-M., Kim, K.-M., et al. (2020). Extending thermotolerance to tomato seedlings by inoculation with SA1 isolate of Bacillus cereus and comparison with exogenous humic acid application. PLoS ONE 15:e232228. doi: 10.1371/journal.pone.02 32228

Khan, M. A., Ullah, I., Waqas, M., Hamayun, M., Khan, A. L., Asaf, S., et al. (2019). Halo-tolerant rhizospheric Arthrobacter woluwensis AK1 mitigates salt stress and induces physio-hormonal changes and expression of GmST1 and GmLAX3 in soybean. Symbiosis 77, 9-21. doi: 10.1007/s13199-018-0562-3

Khan, M. S., Zaidi, A., and Ahmad, E. (2014). "Mechanism of phosphate solubilization and physiological functions of phosphate-solubilizing microorganisms," in Phosphate solubilizing microorganisms, eds M. Khan, A. Zaidi, and J. Musarrat (Cham: Springer), 31-62. doi: 10.1007/978-3-319-08216-5_2

Khan, N., Bano, A., Rahman, M. A., Guo, J., Kang, Z., and Babar, M. A. (2019). Comparative physiological and metabolic analysis reveals a complex mechanism involved in drought tolerance in chickpea (Cicer arietinum L.) induced by PGPR and PGRs. Sci. Rep. 9, 1-19. doi: $10.1038 /$ s41598-019-38702-8

Korir, H., Mungai, N. W., Thuita, M., Hamba, Y., and Masso, C. (2017). Coinoculation effect of rhizobia and plant growth promoting rhizobacteria on common bean growth in a low phosphorus soil. Front. Plant Sci. 8:141. doi: $10.3389 /$ fpls.2017.00141

Kostenko, O., and Bezemer, T. M. (2020). Abiotic and biotic soil legacy effects of plant diversity on plant performance. Front. Ecol. Evol. 8: 87. doi: $10.3389 /$ fevo.2020.00087

Kour, D., Rana, K. L., Sheikh, I., Kumar, V., Yadav, A. N., Dhaliwal, H. S., et al. (2019). Alleviation of drought stress and plant growth promotion by Pseudomonas libanensis EU-LWNA-33, a drought-adaptive phosphorussolubilizing bacterium. Proc. Natl. Acad. Sci. India Sect. B Biol. Sci. 90, 785-795. doi: 10.1007/s40011-019-01151-4

Kramer, J., Özkaya, Ö., and Kümmerli, R. (2019). Bacterial siderophores in community and host interactions. Nat. Rev. Microbiol. 18, 152-163. doi: 10.1038/s41579-019-0284-4

Kudoyarova, G., Arkhipova, T. N., Korshunova, T., Bakaeva, M., Loginov, O., and Dodd, I. C. (2019). Phytohormone mediation of interactions between plants and non-symbiotic growth promoting bacteria under edaphic stresses. Front. Plant Sci. 10:1368. doi: 10.3389/fpls.2019.01368

Kumar, A., Dewangan, S., Lawate, P., Bahadur, I., and Prajapati, S. (2019). "Zinc-solubilizing bacteria: a boon for sustainable agriculture," in Plant Growth Promoting Rhizobacteria for Sustainable Stress Management, eds R. Sayyed, N. Arora, and M. Reddy (Singapore: Springer), 139-155. doi: $10.1007 / 978-981-13-6536-2 \_8$

Kumar, A., and Dubey, A. (2020). Rhizosphere microbiome: Engineering bacterial competitiveness for enhancing crop production. J. Adv. Res. 24, 337-352. doi: $10.1016 /$ j.jare.2020.04.014

Kumar, A., Maurya, B. R., and Raghuwanshi, R. (2015). Characterization of bacterial strains and their impact on plant growth promotion and yield of wheat and microbial populations of soil. Afr. J. Agric. Res. 10, 1367-1375. doi: 10.5897/AJAR2014.8894

Kumar, V., Singh, P., Jorquera, M. A., Sangwan, P., Kumar, P., Verma, A., et al. (2013). Isolation of phytase-producing bacteria from Himalayan soils and their effect on growth and phosphorus uptake of Indian mustard (Brassica juncea). J. Microbiol. Biotechnol. 29, 1361-1369. doi: 10.1007/s11274-013-1299-z

Lade, S. B., Román, C., Del Cueto-Ginzo, A. I., Serrano, L., Sin, E., Achón, M. A., et al. (2019). Differential proteomics analysis reveals that Azospirillium brasilense (Sp7) promotes virus tolerance in maize and tomato seedlings. Eur. J. Plant Pathol. 155, 1241-1263. doi: 10.1007/s10658-019-01852-6

Lal, R. (2015). Restoring soil quality to mitigate soil degradation. Sustainability 7 , 5875-5895. doi: 10.3390/su7055875

Lanteigne, C., Gadkar, V. J., Wallon, T., Novinscak, A., and Filion, M. (2012). Production of DAPG and HCN by Pseudomonas sp. LBUM300 contributes to the biological control of bacterial canker of tomato. Phytopathology 102, 967-973. doi: 10.1094/PHYTO-11-11-0312
Leite, J., Fischer, D., Rouws, L. F., Fernandes-Júnior, P. I., Hofmann, A., Kublik, S., et al. (2017). Cowpea nodules harbor non-rhizobial bacterial communities that are shaped by soil type rather than plant genotype. Front. Plant Sci. 7:2064. doi: 10.3389 /fpls.2016.02064

Li, M., Liu, J., Xu, Y., and Qian, G. (2016). Phosphate adsorption on metal oxides and metal hydroxides: a comparative review. Environ. Rev. 24, 319-332. doi: 10.1139/er-2015-0080

Liu, D., Liu, Y., Zhang, W., Chen, X., and Zou, C. (2017). Agronomic approach of zinc biofortification can increase zinc bioavailability in wheat flour and thereby reduce zinc deficiency in humans. Nutrients 9: 465. doi: 10.3390/nu9050465

Liu, F., Xing, S., Ma, H., Du, Z., and Ma, B. (2013). Cytokinin-producing plant growth-promoting rhizobacteria that confer resistance to drought stress in Platycladus orientalis container seedlings. Appl. Microbiol. Biotechnol. 97, 9155-9164. doi: 10.1007/s00253-013-5193-2

Liu, K., Garrett, C., Fadamiro, H., and Kloepper, J. W. (2016). Antagonism of black rot in cabbage by mixtures of plant growth-promoting rhizobacteria (PGPR). Biocontrol 61, 605-613. doi: 10.1007/s10526-016-9742-3

Liu, Y., Chen, L., Wu, G., Feng, H., Zhang, G., Shen, Q., et al. (2017). Identification of root-secreted compounds involved in the communication between cucumber, the beneficial Bacillus amyloliquefaciens, and the soilborne pathogen Fusarium oxysporum. Mol. Plant Microbe Interact. 30, 53-62. doi: 10.1094/MPMI-07-16-0131-R

Liu, Y., Chen, L., Zhang, N., Li, Z., Zhang, G., Xu, Y., et al. (2016a). Plant-microbe communication enhances auxin biosynthesis by a root-associated bacterium, Bacillus amyloliquefaciens SQR9. Mol. Plant Microbe Interact. 29, 324-330. doi: 10.1094/MPMI-10-15-0239-R

Liu, Y., Kyle, S., and Straight, P. D. (2018a). Antibiotic stimulation of a Bacillus subtilis migratory response. mSphere 3:e00586-17. doi: 10.1128/mSphere.00586-17

Liu, Y., Qin, Q., and Defoirdt, T. (2018b). Does quorum sensing interference affect the fitness of bacterial pathogens in the real world? Environ. Microbiol. 20, 3918-3926. doi: 10.1111/1462-2920.14446

Liu, Y., Wang, R., Zhang, P., Chen, Q., Luo, Q., Zhu, Y., et al. (2016b). The nitrification inhibitor methyl 3-(4-hydroxyphenyl) propionate modulates root development by interfering with auxin signaling via the NO/ROS pathway. Plant Physiol. 171, 1686-1703. doi: 10.1104/pp.16.00670

Lodewyckx, C., Vangronsveld, J., Porteous, F., Moore, E. R., Taghavi, S., Mezgeay, M., et al. (2002). Endophytic bacteria and their potential applications. Crit. Rev. Plant Sci. 21, 583-606. doi: 10.1080/0735-260291044377

Lohitha, S. R., Bhaskara, R. B. V., Sivaprasad, Y., Prathyusha, M., Sujitha, A., Murali Krishna, T., et al. (2016). Molecular characterization and antagonistic potential of phenazine-1-carboxylic acid producing Pseudomonas fluorescens isolates from economically important crops in South India. Int. J. Clin. Biol. Sci. 1, 30-40. doi: 10.7324/ijcbs.2016.123040

Maheshwari, D. K., Dheeman, S., and Agarwal, M. (2015). "Phytohormoneproducing PGPR for sustainable agriculture," in Bacterial Metabolites in Sustainable Agroecosystem, ed D. Maheshwari (Cham: Springer), 159-182. doi: 10.1007/978-3-319-24654-3_7

Mahmood, S., Daur, I., Al-Solaimani, S. G., Ahmad, S., Madkour, M. H., Yasir, M., et al. (2016). Plant growth promoting rhizobacteria and silicon synergistically enhance salinity tolerance of mung bean. Front. Plant Sci. 7:876. doi: $10.3389 /$ fpls.2016.00876

Majeed, A., Abbasi, M. K., Hameed, S., Imran, A., and Rahim, N. (2015). Isolation and characterization of plant growth-promoting rhizobacteria from wheat rhizosphere and their effect on plant growth promotion. Front. Microbiol. 6:198. doi: 10.3389/fmicb.2015.00198

Maksimov, I., Abizgil'dina, R., and Pusenkova, L. (2011). Plant growth promoting rhizobacteria as alternative to chemical crop protectors from pathogens. Appl. Biochem. Microbiol. 47, 333-345. doi: 10.1134/S0003683811040090

Malhotra, H., Sharma, S., and Pandey, R. (2018). "Phosphorus nutrition: plant growth in response to deficiency and excess," in Plant Nutrients and Abiotic Stress Tolerance, eds M. Hasanuzzaman, M. Fujita, H. Oku, K. Nahar, and B. Hawrylak-Nowak (Singapore: Springer), 171-190. doi: 10.1007/978-981-10-9044-8_7

Martínez-Hidalgo, P., Galindo-Villardón, P., Trujillo, M. E., Igual, J. M., and Martínez-Molina, E. (2014). Micromonospora from nitrogen fixing nodules of alfalfa (Medicago sativa L.). A new promising plant probiotic bacteria. Sci. Rep. 4:6389. doi: $10.1038 /$ srep06389 
Masood, S., Zhao, X. Q., and Shen, R. F. (2020). Bacillus pumilus promotes the growth and nitrogen uptake of tomato plants under nitrogen fertilization. Sci. Hortic. 272:109581. doi: 10.1016/j.scienta.2020.109581

Matos, A. D., Gomes, I. C., Nietsche, S., Xavier, A. A., Gomes, W. S., Dos Santos Neto, J. A., et al. (2017). Phosphate solubilization by endophytic bacteria isolated from banana trees. An. Acad. Bras. Cienc. 89, 2945-2954. doi: 10.1590/0001-3765201720160111

Mcnear, D. H. Jr. (2013). The rhizosphere-roots, soil and everything in between. Nat. Educ. Knowl. 4:1. Available online at: http://www.nature.com/scitable/ knowledge/library/the-rhizosphere-roots-soil-and- 67500617

Mehnaz, S. (2013). "Secondary metabolites of Pseudomonas aurantiaca and their role in plant growth promotion," in Plant Microbe Symbiosis: Fundamentals and Advances, ed N. Arora (New Dehli: Springer), 373-393. doi: 10.1007/978-81-322-1287-4_14

Mirza, B. S., Potisap, C., Nüsslein, K., Bohannan, B. J., and Rodrigues, J. L. (2014). Response of free-living nitrogen-fixing microorganisms to land use change in the Amazon rainforest. Appl. Environ. Microbiol. 80, 281-288. doi: 10.1128/AEM.02362-13

Mukhtar, T., Smith, D., Sultan, T., Seleiman, M. F., Alsadon, A. A., Ali, S., et al. (2020). Mitigation of heat stress in Solanum lycopersicum l. by acc-deaminase and exopolysaccharide producing Bacillus cereus: effects on biochemical profiling. Sustainability 12, 2159. doi: 10.3390/su12062159

Muleta, A., and Assefa, F. (2018). Isolation and screening of antibiotic producing actinomycetes from rhizosphere and agricultural soils. Afr. J. Biotechnol. 17, 700-715. doi: 10.5897/AJB2017.16080

Mun, B.-G., Lee, W.-H., Kang, S.-M., Lee, S.-U., Lee, S.-M., Lee, D. Y., et al. (2020). Streptomyces sp. LH 4 promotes plant growth and resistance against Sclerotinia sclerotiorum in cucumber via modulation of enzymatic and defense pathways. Plant Soil 448, 87-103. doi: 10.1007/s11104-019-04411-4

Mustafa, S., Kabir, S., Shabbir, U., and Batool, R. (2019). Plant growth promoting rhizobacteria in sustainable agriculture: from theoretical to pragmatic approach. Symbiosis 78, 115-123. doi: 10.1007/s13199-019-00 602-w

Nadeem, S. M., Zahir, Z. A., Naveed, M., Asghar, H. N., and Arshad, M. (2010). Rhizobacteria capable of producing acc-deaminase may mitigate salt stress in wheat. Soil Sci. Soc. Am. J. 74, 533-542. doi: 10.2136/sssaj20 08.0240

Naqqash, T., Hameed, S., Imran, A., Hanif, M. K., Majeed, A., and Van Elsas, J. D. (2016). Differential response of potato toward inoculation with taxonomically diverse plant growth promoting rhizobacteria. Front. Plant Sci. 7:144. doi: $10.3389 /$ fpls.2016.00144

Naqqash, T., Imran, A., Hameed, S., Shahid, M., Majeed, A., Iqbal, J., et al. (2020). First report of diazotrophic Brevundimonas spp. as growth enhancer and root colonizer of potato. Sci. Rep. 10, 1-14. doi: 10.1038/s41598-020-69782-6

Naseem, H., and Bano, A. (2014). Role of plant growth-promoting rhizobacteria and their exopolysaccharide in drought tolerance of maize. J. Plant Interact. 9, 689-701. doi: 10.1080/17429145.2014.902125

Nash, M. V., Anesio, A. M., Barker, G., Tranter, M., Varliero, G., EloeFadrosh, E. A., et al. (2018). Metagenomic insights into diazotrophic communities across Arctic glacier forefields. FEMS Microbiol. Ecol. 94:fiyl14. doi: 10.1093/femsec/fiyl14

Nautiyal, C. S., Srivastava, S., Chauhan, P. S., Seem, K., Mishra, A., and Sopory, S. K. (2013). Plant growth-promoting bacteria Bacillus amyloliquefaciens NBRISN13 modulates gene expression profile of leaf and rhizosphere community in rice during salt stress. Plant Physiol. Biochem. 66, 1-9. doi: 10.1016/j.plaphy.2013.01.020

Nawaz, A., Shahbaz, M., Imran, A., Marghoob, U., Imtiaz, M., Mubeen, F., et al. (2020). Potential of salt tolerant PGPR in growth and yield augmentation of wheat (Triticum aestivum L.) under saline conditions. Front. Microbiol. 11:2019. doi: 10.3389/fmicb.2020.02019

Naziya, B., Murali, M., and Amruthesh, K. N. (2020). Plant Growth-Promoting Fungi (PGPF) Instigate plant growth and induce disease resistance in Capsicum annuum L. upon infection with Colletotrichum capsici (Syd.) Butler \& Bisby. Biomolecules 10:41. doi: 10.3390/biom10010041

Naznin, H. A., Kimura, M., Miyazawa, M., and Hyakumachi, M. (2013). Analysis of volatile organic compounds emitted by plant growth-promoting fungus Phoma sp. GS8-3 for growth promotion effects on tobacco. Microbes Environ. 28, 42-49. doi: 10.1264/jsme2.ME12085
Nia, S. H., Zarea, M. J., Rejali, F., and Varma, A. (2012). Yield and yield components of wheat as affected by salinity and inoculation with Azospirillum strains from saline or non-saline soil. J. Saudi Soc. Agric. Sci.1, 113-121. doi: $10.1016 /$ j.jssas.2012.02.001

Noguero, M., Atif, R. M., Ochatt, S., and Thompson, R. D. (2013). The role of the DNA-binding One Zinc Finger (DOF) transcription factor family in plants. Plant Sci. 209, 32-45. doi: 10.1016/j.plantsci.2013.03.016

O’Brien, J. A., Vega, A., Bouguyon, E., Krouk, G., Gojon, A., Coruzzi, G., et al. (2016). Nitrate transport, sensing, and responses in plants. Mol. Plant 9, 837-856. doi: 10.1016/j.molp.2016.05.004

Oleńska, E., Małek, W., Wójcik, M., Swiecicka, I., Thijs, S., and Vangronsveld, J. (2020). Beneficial features of plant growth-promoting rhizobacteria for improving plant growth and health in challenging conditions: a methodical review. Sci. Total Environ. 743:140682. doi: 10.1016/j.scitotenv.2020.140682

Ortiz, N., Armada, E., Duque, E., Roldán, A., and Azcón, R. (2015). Contribution of arbuscular mycorrhizal fungi and/or bacteria to enhancing plant drought tolerance under natural soil conditions: effectiveness of autochthonous or allochthonous strains. J. Plant Physiol. 174, 87-96. doi: $10.1016 /$ j.jplph.2014.08.019

Osugi, A., and Sakakibara, H. (2015). Q\&A: how do plants respond to cytokinins and what is their importance? BMC Biol. 13:120. doi: 10.1186/s12915-015-0214-5

Park, Y.-G., Mun, B.-G., Kang, S.-M., Hussain, A., Shahzad, R., Seo, C.-W., et al. (2017). Bacillus aryabhattai SRB02 tolerates oxidative and nitrosative stress and promotes the growth of soybean by modulating the production of phytohormones. PLOS ONE 12:e0173203. doi: 10.1371/journal.pone.0173203

Philippot, L., Raaijmakers, J. M., Lemanceau, P., and Van Der Putten, W. H. (2013). Going back to the roots: the microbial ecology of the rhizosphere. Nat. Rev. Microbiol. 11, 789-799. doi: 10.1038/nrmicro3109

Pieterse, C. M., Zamioudis, C., Berendsen, R. L., Weller, D. M., Van Wees, S. C., and Bakker, P. A. (2014). Induced systemic resistance by beneficial microbes. Ann. Rev. Phytopathol. 52, 347-375. doi: 10.1146/annurev-phyto-082712-102340

Pourbabaee, A. A., Shoaibi, F., Emami, S., and Alikhani, H. A. (2018). The potential contribution of siderophore producing bacteria on growth and $\mathrm{Fe}$ ion concentration of sunflower (Helianthus annuus L.) under water stress. J. Plant Nut. 41, 619-626. doi: 10.1080/01904167.2017.1406112

Premachandra, D., Hudek, L., and Brau, L. (2016). Bacterial modes of action for enhancing of plant growth. J. Biotechnol. Biomat. 6, 1-8. doi: 10.4172/2155-952X.1000236

Qaisrani, M. M., Mirza, M. S., Zaheer, A., and Malik, K. A. (2014). Isolation and identification by $16 \mathrm{~S}$ rRNA sequence analysis of Achromobacter, Azospirillum and Rhodococcus strains from the rhizosphere of maize and screening for the beneficial effect on plant growth. Pak. J. Agri. Sci. 51, 91-99. Available online at: https://pakjas.com.pk/papers/2247.pdf

Quiza, L., St-Arnaud, M., and Yergeau, E. (2015). Harnessing phytomicrobiome signaling for rhizosphere microbiome engineering. Front. Plant Sci. 6:507. doi: 10.3389 /fpls.2015.00507

Raheem, A., Shaposhnikov, A., Belimov, A. A., Dodd, I. C., and Ali, B. (2018). Auxin production by rhizobacteria was associated with improved yield of wheat (Triticum aestivum L.) under drought stress. Arch. Agron. Soil Sci. 64, 574-587. doi: 10.1080/03650340.2017.1362105

Rajamanickam, S., and Nakkeeran, S. (2020). Flagellin of Bacillus amyloliquefaciens works as a resistance inducer against groundnut bud necrosis virus in chilli (Capsicum annuum L.). Arch. Virol. 165, 1585-1597. doi: 10.1007/s00705-020-04645-z

Rajput, L., Imran, A., Mubeen, F., and Hafeez, F. Y. (2013). Salt-tolerant PGPR strain Planococcus rifietoensis promotes the growth and yield of wheat (Triticum aestivum L.) cultivated in saline soil. Pak. J. Bot. 45, 1955-1962. Available online at: http://www.pakbs.org/pjbot/PDFs/45(6)/15.pdf

Rajput, L., Imran, A., Mubeen, F., and Hafeez, F. Y. (2018). Wheat (Triticum aestivum L.) growth promotion by halo-tolerant PGPR-consortium. Soil Environ. 37, 178-189. doi: 10.25252/SE/18/61522

Rakshit, A., Sunita, K., Pal, S., Singh, A., and Singh, H. B. (2015). "Bio-priming mediated nutrient use efficiency of crop species," in Nutrient Use Efficiency: From Basics to Advances, eds A. Rakshit, H. B. Singh, and A. Sen (New Dehli: Springer), 181-191. doi: 10.1007/978-81-322-2169-2_12

Ramesh, A., Sharma, S. K., Sharma, M. P., Yadav, N., and Joshi, O. P. (2014). Inoculation of zinc solubilizing Bacillus aryabhattai strains for 
improved growth, mobilization and biofortification of zinc in soybean and wheat cultivated in Vertisols of central India. Appl. Soil Ecol. 73, 87-96. doi: 10.1016/j.apsoil.2013.08.009

Rasul, M., Yasmin, S., Suleman, M., Zaheer, A., Reitz, T., Tarkka, M. T., et al. (2019). Glucose dehydrogenase gene containing phosphobacteria for biofortification of phosphorus with growth promotion of rice. Microbiol. Res. 223, 1-12. doi: 10.1016/j.micres.2019.03.004

Reed, S. C., Yang, X., and Thornton, P. E. (2015). Incorporating phosphorus cycling into global modeling efforts: a worthwhile, tractable endeavor. New Phytol. 208, 324-329. doi: 10.1111/nph.13521

Reghuvaran, A., Jacob, K. K., and Ravindranath, A. D. (2012). Isolation and characterization of nitrogen fixing bacteria from raw coir pith. Afri. J. Biotechnol. 11, 7063-7071. doi: 10.5897/AJB11.2205

Richardson, A. E., and Simpson, R. J. (2011). Soil microorganisms mediating phosphorus availability update on microbial phosphorus. Plant Physiol. 156, 989-996. doi: 10.1104/pp.111.175448

Rodríguez, M., Torres, M., Blanco, L., Béjar, V., Sampedro, I., and Llamas, I. (2020). Plant growth-promoting activity and quorum quenching-mediated biocontrol of bacterial phytopathogens by Pseudomonas segetis strain P6. Sci. Rep. 10, 1-12. doi: 10.1038/s41598-020-61084-1

Romero, M., Martin-Cuadrado, A.-B., and Otero, A. (2012). Determination of whether quorum quenching is a common activity in marine bacteria by analysis of cultivable bacteria and metagenomic sequences. Appl. Environ. Microbiol. 78, 6345-6348. doi: 10.1128/AEM.01266-12

Saarenheimo, J., Tiirola, M. A., and Rissanen, A. J. (2015). Functional gene pyrosequencing reveals core proteobacterial denitrifiers in boreal lakes. Front. Microbiol. 6:674. doi: 10.3389/fmicb.2015.00674

Sagervanshi, A., Priyanka, K., Anju, N., and Ashwani, K. (2012). Isolation and characterization of phosphate solubilizing bacteria from and agriculture soil. Int. J. Life Sci. Pharma Res. 23, 256-266. Available online at: https://www.ijlpr. com/admin/php/uploads/124_pdf.pdf

Sah, S., Singh, N., and Singh, R. (2017). Iron acquisition in maize (Zea mays L.) using Pseudomonas siderophore. Biotech 7, 1-7. doi: $10.1007 / \mathrm{s} 13205-017-0772-\mathrm{Z}$

Sahu, G., and Sindhu, S. (2011). Disease control and plant growth promotion of green gram by siderophore producing Pseudomonas sp. Res. J. Microbiol. 6, 735. doi: 10.3923/jm.2011. 735.749

Saraf, M., Jha, C. K., and Patel, D. (2010). "The role of ACC deaminase producing PGPR in sustainable agriculture," in Plant Growth and Health Promoting Bacteria, ed D. Maheshwari (Berlin, Heidelberg: Springer), 365-385. doi: 10.1007/978-3-642-13612-2_16

Saravanan, V., Kumar, M. R., and Sa, T. (2011). "Microbial zinc solubilization and their role on plants," in Bacteria in Agrobiology: Plant Nutrient Management, ed D. Maheshwari (Berlin, Heidelberg: Springer), 47-63. doi: 10.1007/978-3-642-21061-7_3

Sarkar, J., Chakraborty, B., and Chakraborty, U. (2018). Plant growth promoting rhizobacteria protect wheat plants against temperature stress through antioxidant signalling and reducing chloroplast and membrane injury. J. Plant Growth Regul. 37, 1396-1412. doi: 10.1007/s00344-018-9789-8

Schmid, M. W., Hahl, T., Van Moorsel, S. J., Wagg, C., De Deyn, G. B., and Schmid, B. (2018). Rhizosphere bacterial community composition depends on plant diversity legacy in soil and plant species identity. BioRxiv [Preprint]. 287235. doi: $10.1101 / 287235$

Schoebitz, M., Ceballos, C., and Ciamp, L. (2013). Effect of immobilized phosphate solubilizing bacteria on wheat growth and phosphate uptake. J. Soil Sci. Plant Nut. 13, 1-10. doi: 10.4067/S0718-95162013005000001

Seleim, M., Saead, F., Abd-El-Moneem, K., and Abo-Elyousr, K. (2011). Biological control of bacterial wilt of tomato by plant growth promoting rhizobacteria. Plant Pathol. J. 10, 146-153. doi: 10.3923/ppj.2011.146.153

Shahzad, R., Khan, A. L., Bilal, S., Waqas, M., Kang, S.-M., and Lee, I.-J. (2017). Inoculation of abscisic acid-producing endophytic bacteria enhances salinity stress tolerance in Oryza sativa. Environ. Exp. Bot. 136, 68-77. doi: 10.1016/j.envexpbot.2017.01.010

Shaikh, S., and Saraf, M. (2017). Zinc biofortification: Strategy to conquer zinc malnutrition through zinc solubilizing PGPR's. Biomed. J. Sci. Tech. Res. 1, 224-226. doi: 10.26717/BJSTR.2017.01.000158
Shameer, S., and Prasad, T. (2018). Plant growth promoting rhizobacteria for sustainable agricultural practices with special reference to biotic and abiotic stresses. Plant Growth Regul. 84, 603-615. doi: 10.1007/s10725-017-0365-1

Sharma, S., Kumar, V., and Tripathi, R. B. (2011). Isolation of phosphate solubilizing microorganism (PSMs) from soil. J. Microbiol. Biotechnol. Res. 1, 90-95. Available online at: https://www.researchgate.net/publication/ 267368923

Sharma, S. B., Sayyed, R. Z., Trivedi, M. H., and Gobi, T. A. (2013). Phosphate solubilizing microbes: sustainable approach for managing phosphorus deficiency in agricultural soils. SpringerPlus 2:587. doi: 10.1186/2193-1801-2-587

Shen, X., Hu, H., Peng, H., Wang, W., and Zhang, X. (2013). Comparative genomic analysis of four representative plant growth-promoting rhizobacteria in Pseudomonas. BMC Genomics 14:271. doi: 10.1186/1471-2164-14-271

Singh, S. K. (2020). "Microbes for iron chlorosis remediation in Peach," in Biostimulants in Plant Science, ed S. Mirmajlessi, and R. Radhakrishnan (London: IntechOpen). doi: 10.5272/intechopen.B2916

Staudinger, C., Mehmeti-Tershani, V., Gil-Quintana, E., Gonzalez, E. M., Hofhansl, F., Bachmann, G., et al. (2016). Evidence for a rhizobia-induced drought stress response strategy in Medicago truncatula. J. Proteomics 136, 202-213. doi: 10.1016/j.jprot.2016.01.006

Stringlis, I. A., Yu, K., Feussner, K., De Jonge, R., Van Bentum, S., Van Verk, M. C., et al. (2018). MYB72-dependent coumarin exudation shapes root microbiome assembly to promote plant health. Proc. Natl. Acad. Sci. U.S.A. 115, E5213E5222. doi: 10.1073/pnas.1722335115

Subramanium, N., and Sundaram, L. (2020). Siderophore producing Pseudomonas spp. isolated from rhizospheric soil and enhancing iron content in Arachis hypogaea L. plant. Int. J. Agric. Technol. 16, 429-442. Available online at: http://ijat-aatsea.com/pdf/v16_n2_2020_March/18_IJAT_16(2)_2020_ Subramanium, \%20N.\%20.pdf

Suleman, M., Yasmin, S., Rasul, M., Yahya, M., Atta, B. M., and Mirza, M. S. (2018). Phosphate solubilizing bacteria with glucose dehydrogenase gene for phosphorus uptake and beneficial effects on wheat. PLOS ONE 13:e0204408. doi: 10.1371/journal.pone.0204408

Tahir, M., and Sarwar, M. A. (2013). Plant growth promoting rhizobacteria (PGPR): a budding complement of synthetic fertilizers for improving crop production. Pak. J. Life Soc. Sci. 11, 1-7.

Tank, N., and Saraf, M. (2010). Salinity-resistant plant growth promoting rhizobacteria ameliorates sodium chloride stress on tomato plants. J. Plant Interact. 5, 51-58. doi: 10.1080/17429140903125848

Tariq, M., Hameed, S., Yasmeen, T., and Ali, A. (2012). Non-rhizobial bacteria for improved nodulation and grain yield of mung bean [Vigna radiata (L.) Wilczek]. Afr. J. Biotechnol. 11, 15012-15019. doi: 10.5897/AJB11.3438

Tariq, M., Noman, M., Ahmed, T., Hameed, A., Manzoor, N., and Zafar, M. (2017). Antagonistic features displayed by plant growth promoting rhizobacteria (PGPR): a review. Afr. J. Plant Sci. 1, 38-43. doi: 10.29328/journal.jpsp.1001004

Thomas, J., Kim, H. R., Rahmatallah, Y., Wiggins, G., Yang, Q., Singh, R., et al. (2019). RNA-seq reveals differentially expressed genes in rice (Oryza sativa) roots during interactions with plant-growth promoting bacteria, Azospirillum brasilense. PLoS ONE 14:e0217309. doi: 10.1371/journal.pone.0217309

Tiwari, S., Lata, C., Chauhan, P. S., and Nautiyal, C. S. (2016). Pseudomonas putida attunes morphophysiological, biochemical and molecular responses in Cicer arietinum L. during drought stress and recovery. Plant Physiol. Biochem. 99, 108-117. doi: 10.1016/j.plaphy.2015.11.001

Torres, M., Hong, K.-W., Chong, T.-M., Reina, J. C., Chan, K.-G., Dessaux, Y., et al. (2019). Genomic analyses of two Alteromonas stellipolaris strains reveal traits with potential biotechnological applications. Sci. Rep. 9, 1-14. doi: 10.1038/s41598-018-37720-2

Torres-Cortés, G., Bonneau, S., Bouchez, O., Genthon, C., Briand, M., Jacques, M.-A., et al. (2018). Functional microbial features driving community assembly during seed germination and emergence. Front. Plant Sci. 9:902. doi: $10.3389 /$ fpls.2018.00902

Vaid, S. K., Kumar, B., Sharma, A., Shukla, A., and Srivastava, P. (2014). Effect of $\mathrm{Zn}$ solubilizing bacteria on growth promotion and $\mathrm{Zn}$ nutrition of rice. J. Soil Sci. Plant Nutr. 14, 889-910. doi: 10.4067/S0718-95162014005000071

Vardharajula, S., Zulfikar Ali, S., Grover, M., Reddy, G., and Bandi, V. (2011). Drought-tolerant plant growth promoting Bacillus spp.: effect on growth, 
osmolytes, and antioxidant status of maize under drought stress. J. Plant Interact. 6, 1-14. doi: 10.1080/17429145.2010.535178

Velázquez, E., Martínez-Hidalgo, P., Carro, L., Alonso, P., Peix, A., Trujillo, M., et al. (2013). "Nodular endophytes: an untapped diversity," in Beneficial PlantMicrobial Interactions, eds M. B. González and J. González-López (Boca Raton, FL: Taylor and Francis/CRC Press), 214-236. doi: 10.1201/b15251-11

Villegas, J. M., Way, M. O., Pearson, R. A., and Stout, M. J. (2017). Integrating soil silicon amendment into management programs for insect pests of drill-seeded rice. Plants 6:33. doi: 10.3390/plants6030033

Walters, J. P., Archer, D. W., Sassenrath, G. F., Hendrickson, J. R., Hanson, J. D., Halloran, J. M., et al. (2016). Exploring agricultural production systems and their fundamental components with system dynamics modelling. Ecol. Model. 333, 51-65. doi: 10.1016/j.ecolmodel.2016.04.015

Wei, R., Wang, X., Zhang, W., Shen, J., Zhang, H., Gao, Y., et al. (2020). The improved phosphorus utilization and reduced phosphorus consumption of ppk-expressing transgenic rice. Field Crops Res. 248:107715. doi: 10.1016/j.fcr.2020.107715

Wilkins, D., Lu, X.-Y., Shen, Z., Chen, J., and Lee, P. K. (2015). Pyrosequencing of $m c r A$ and archaeal $16 \mathrm{~S}$ rRNA genes reveals diversity and substrate preferences of methanogen communities in anaerobic digesters. Appl. Environ. Microbiol. 81, 604-613. doi: 10.1128/AEM.02566-14

Wong, W., Tan, S., Ge, L., Chen, X., and Yong, J. (2015). "The importance of phytohormones and microbes in biofertilizers," in Bacterial Metabolites in Sustainable Agroecosystem, ed D. Maheshwari (Cham: Springer), 105-158. doi: 10.1007/978-3-319-24654-3_6

Xiaohui, F., Zhang, S., Xiaodan, M., Yuncong, L., Yuqing, F., and Zhiguang, L. (2017). Effects of plant growth-promoting rhizobacteria and $\mathrm{N}$ source on plant growth and $\mathrm{N}$ and $\mathrm{P}$ uptake by tomato grown on calcareous soils. Pedosphere 27, 1027-1036. doi: 10.1016/S1002-0160(17)60379-5

Xie, J., Shi, H., Du, Z., Wang, T., Liu, X., and Chen, S. (2016). Comparative genomic and functional analysis reveal conservation of plant growth promoting traits in Paenibacillus polymyxa and its closely related species. Sci. Rep. 6, 1-12. doi: 10.1038/srep21329

Yadav, A. N., Sachan, S. G., Verma, P., Kaushik, R., and Saxena, A. K. (2016). Cold active hydrolytic enzymes production by psychrotrophic Bacilli isolated from three sub-glacial lakes of NW Indian Himalayas. J. Basic Microbiol. 56, 294-307. doi: 10.1002/jobm.201500230

Yasmin, S., Zaka, A., Imran, A., Zahid, M. A., Yousaf, S., Rasul, G., et al. (2016). Plant growth promotion and suppression of bacterial leaf blight in rice by inoculated bacteria. PLoS ONE 11:e0160688. doi: 10.1371/journal.pone.0160688
Ye, T., Zhou, T., Li, Q., Xu, X., Fan, X., Zhang, L., et al. (2020). Cupriavidus sp. HN-2, a novel quorum quenching bacterial isolate, is a potent biocontrol agent against Xanthomonas campestris pv. campestris. Microorganisms 8:45. doi: 10.3390/microorganisms 8010045

Yuan, J., Zhao, J., Wen, T., Zhao, M., Li, R., Goossens, P., et al. (2018). Root exudates drive the soil-borne legacy of aboveground pathogen infection. Microbiome 6, 1-12. doi: 10.1186/s40168-0180537-x

Zaheer, A., Mirza, B. S., Mclean, J. E., Yasmin, S., Shah, T. M., Malik, K. A., et al. (2016). Association of plant growth-promoting Serratia spp. with the root nodules of chickpea. Res. Microbiol. 167, 510-520. doi: 10.1016/j.resmic.2016.04.001

Zahid, M. (2015). Isolation and identification of indigenous plant growth promoting rhizobacteria from Himalayan region of Kashmir and their effect on improving growth and nutrient contents of maize (Zea mays L.). Front. Microbiol. 6:207. doi: 10.3389/fmicb.2015.00207

Zhang, T., Zhao, Y., Ye, J., Cao, X., Xu, C., Chen, B., et al. (2019). Establishing CRISPR/Cas13a immune system conferring RNA virus resistance in both dicot and monocot plants. Plant Biotechnol. J. 17:1185. doi: 10.1111/pbi. 13095

Zhang, X., Zhang, D., Sun, W., and Wang, T. (2019). The adaptive mechanism of plants to iron deficiency via iron uptake, transport, and homeostasis. Int. J. Mol. Sci. 20:2424. doi: 10.3390/ijms20 102424

Ziadi, N., Whalen, J. K., Messiga, A. J., and Morel, C. (2013). "Assessment and modeling of soil available phosphorus in sustainable cropping systems," in Advances in Agronomy ed D. Sparks (San Diego, CA: Elsevier), 85-126. doi: 10.1016/B978-0-12-417187-9. 00002-4

Conflict of Interest: The authors declare that the research was conducted in the absence of any commercial or financial relationships that could be construed as a potential conflict of interest.

Copyright (c) 2021 Hakim, Naqqash, Nawaz, Laraib, Siddique, Zia, Mirza and Imran. This is an open-access article distributed under the terms of the Creative Commons Attribution License (CC BY). The use, distribution or reproduction in other forums is permitted, provided the original author(s) and the copyright owner(s) are credited and that the original publication in this journal is cited, in accordance with accepted academic practice. No use, distribution or reproduction is permitted which does not comply with these terms. 